I Universidade do Estado do Rio de Janeiro (Uerj), Instituto de Estudos Sociais e Políticos, Rio de Janeiro, RJ, Brasil

marciarangelcandido@gmail.com https://orcid.org/0000-0003-3466-000X

II Universidade de Brasília (UnB), Instituto de Ciência Política, Brasília, DF, Brasil

danusamarques@gmail.com https://orcid.org/oooo-00o I-9845-4593

III Universidade Federal do ABC (UFABC), Programas de Pós-Graduação em Políticas Públicas e em Planejamento e Gestão do Território, Santo André, SP, Brasil

vanessa.oliveira@ufabc.edu.br

https://orcid.org/oooo-000I-89I6-498I

Iv Universidade de Brasília (UnB), Instituto de Ciência Política, Brasília, DF, Brasil

flaviabiroli@gmail.com

https://orcid.org/00oo-0003-2723-473I

\author{
Marcia Rangel Candido' \\ Danusa Marques" \\ Vanessa Elias de Oliveiral'I \\ Flávia Biroliv
}

\title{
AS CIÊNCIAS SOCIAIS NA PANDEMIA DA COVID-19: ROTINAS DE TRABALHO E DESIGUALDADES*
}

A pandemia da covid-Ig afetou drasticamente a vida em sociedade e a organização dos espaços de convívio coletivo. As condições sociais de produção e reprodução da ciência se transformaram como parte dessa crise global sem precedentes. A exigência de isolamento social provocou a limitação de uso dos espaços universitários, com o impedimento de aulas presenciais ou a alteração nos locais tradicionais de desenvolvimento de pesquisas. Congressos acadêmicos foram cancelados, adiados ou adaptados aos meios virtuais, o que ocasionou rupturas inesperadas também na criação de redes e na comunicação científica tradicional. A despeito de alguns desafios serem mais gerais e comuns em meio à comunidade de cientistas, estudos têm mostrado que há variações substantivas na magnitude dos problemas enfrentados por diferentes perfis de gênero e raça, assim como por pesquisadores/as de distintas subáreas do conhecimento (Myers et al., 2020; Staniscuaski et al., 2020; Breuning et al., 2020; Cui, Ding \& $\mathrm{Zhu}, 2020)$.

O objetivo do presente artigo é analisar como tal crise repercutiu nas rotinas de trabalho acadêmico de diferentes áreas das ciências sociais no Brasil. O estudo se baseia nos principais resultados de um survey online promovido pela Associação Brasileira de Ciência Política (ABCP), com o apoio da Associação Nacional de Pós-Graduação e Pesquisa em Ciências Sociais (Anpocs), da Associação Brasileira de Relações Internacionais (Abri), da Associação Brasileira de Antropologia (ABA) e da Sociedade Brasileira de Sociologia (SBS). 
Os surveys constituem um dos métodos de pesquisa utilizados para identificar características de comunidades acadêmicas, conjunturas e perspectivas de aprimoramento de categorias profissionais (ver, entre outros, Vallejo, 2017). Na ciência política brasileira o método foi empregado antes mesmo da criação de cursos de ensino superior especializados na área, com o intuito de mapear os grupos que se mobilizavam em torno da temática e verificar a possibilidade de reforçar conexões de trabalho entre eles (Michetti \& Miceli, I969). ${ }^{\text {I }}$ A circulação de questionários também já embasou debates sobre fatores como as desigualdades, as discriminações e as violências no interior de disciplinas (Novkov \& Barclay, 20I0; Allen \& Savigny, 20I6; Aktinson et al., 20I8; Norris, 2020) ou no âmbito das experiências universitárias de uma maneira geral (Palumbo, 20I7; USP Mulheres, 2018).

Mais recentemente, a aplicação de surveys nos meios acadêmicos tem colaborado para a apreensão das dificuldades específicas dos espaços de formação educacional e trabalho científico advindas da disseminação da covid-ı 9 . Kyle Myers et al. (2020) aplicaram questionários na Europa e nos Estados Unidos e mostraram que há discrepâncias entre grupos por áreas de especialização e gênero: aqueles que necessitam de laboratórios para conduzir projetos tiveram queda mais brusca de dispêndio de tempo gasto em pesquisas, assim como as pessoas com dependentes jovens, especialmente as mulheres, que se viram obrigadas a reorganizar as tarefas de cuidado.

O dado em relação à sobrecarga feminina também apareceu em um levantamento feito no Brasil. A pesquisa "Parent in Science", centralizada na questão da maternidade e coordenada por Fernanda Staniscuaski (2020), demonstrou que homens brancos sem filhos reportaram menos impactos em produtividade do que mulheres brancas com filhos e mulheres negras, mães ou não. Esse estudo, no entanto, não divulgou especificidades por disciplinas. Marijke Breuning et al. (2020), por outro lado, aplicaram questionários específicos à comunidade de cientistas políticos(as), difundidos pela International Studies Association (ISA). Com maioria de participantes vinculada a instituições estadunidenses, o trabalho salientou que homens e mulheres responderam de modo similar sobre as consequências negativas da pandemia, mas que nas questões abertas as clivagens de gênero puderam aparecer.

As disparidades de gênero e as oscilações entre campos disciplinares também foram exploradas no working paper de Cui, Ding e Zhu (2020). Os autores examinaram publicações no maior repositório de preprints do mundo, o Social Science Research Network (SSRN), e aferiram incremento de $35 \%$ nas submissões de homens e decréscimo de $13,9 \%$ na de mulheres. ${ }^{2}$ Ainda que muitas áreas das ciências sociais tenham seguido essa tendência, há contrastes. Para mencionar um, na antropologia a diminuição no envio de trabalhos foi geral, enquanto na ciência política a assimetria entre os gêneros se ampliou, aprofundando a sub-representação das mulheres na autoria de textos e a prevalência dos homens. 
Essas informações não necessariamente revelam surpresas às/aos pesquisadoras(es) que lidam com desigualdades. Em um mundo social profundamente marcado por hierarquias de gênero, raça e classe, é previsível que as fases de adversidade acabem por atingir mais algumas parcelas da sociedade que outras. A maturidade dos estudos sobre desigualdades em certas áreas das ciências sociais brasileiras, contudo, contrasta com o tratamento reduzido do tema no debate público entre as comunidades acadêmicas e as agências de fomento e avaliação da produtividade científica. A maior parte dos parâmetros de seleção de profissionais, determinação de qualidade de instituições de ensino e das demais atribuições de trabalho é convencionada por critérios de meritocracia, que operam com suposta neutralidade frente às diferenças sociais e pode, por isso, silenciosamente reproduzir vieses.

Para identificar os padrões e as desigualdades no trabalho acadêmico dos(as) cientistas sociais brasileiros(as) durante a pandemia da covid-I9, o presente artigo apresenta a metodologia utilizada no survey realizado e os dados do perfil de respondentes, de suas percepções sobre os efeitos da pandemia nas atividades de formação, ensino e pesquisa, bem como das possibilidades de organização do tempo para as funções domésticas e de cuidado. Nele demonstramos que, embora o impacto negativo seja relatado pela maioria dos(as) respondentes, as assimetrias de raça e gênero e as diferenças nas disciplinas de atuação precisam ser consideradas. Ao final, argumentamos que as disparidades evidenciadas pela pesquisa devem ser ponderadas nos processos de avaliação da produtividade dos(as) cientistas sociais brasileiros(as), assim como na promoção da diversidade no mercado de trabalho.

\section{METODOLOGIA}

O survey que embasa esta análise, intitulado "O impacto da pandemia nas rotinas de trabalho acadêmico nas ciências sociais", foi elaborado alguns meses depois de a Organização Mundial da Saúde (OMS) ter decretado ser a covid-ı 9 uma pandemia. A intenção foi produzir rapidamente diagnósticos que pudessem dimensionar quais dificuldades deveriam ser objeto especial de atenção da comunidade. As versões iniciais do questionário foram submetidas a um préteste, por meio de sua aplicação em um conjunto de acadêmicos(as) de distintas áreas das ciências sociais. A despeito do caráter coletivo dessa construção, entendemos que a decisão do conteúdo final foi de responsabilidade nossa.

O envio do survey ocorreu por meio virtual entre io de junho e i5 de julho de 2020. A divulgação foi realizada nas redes sociais (e-mail, Facebook, Instagram e Twitter) de associações profissionais (ABA, ABCP, Abri, Anpocs e $\mathrm{SBS}$ ), bem como nas páginas de instituições de ensino e pesquisa e nos grupos de WhatsApp de docentes, estudantes e pesquisadores(as). Ao todo, foram computados 1.073 respondentes de todas as regiões do país, em sua maioria (98\%) de nacionalidade brasileira. Não podemos desconsiderar o viés de seleção que 
o método implica, já que certamente atingiu mais as/os pesquisadoras(es) que compõem nossa rede de contatos. Todavia, levando em conta a capilaridade das redes sociais utilizadas para divulgação do questionário, seu alcance foi significativamente ampliado, o que explica a obtenção de respostas de pesquisadores(as) de todo o país.

Mesmo assim, ressaltamos que nossa amostra não é estatisticamente representativa da população de acadêmicos de ciências sociais. Nas condições atuais de pesquisa social em formato remoto e emergencial, optamos por um survey online com difusão pelas principais associações científicas dos grupos que buscamos atingir, mantendo o escopo de respostas aberto a profissionais de vínculos variados com a academia. Ainda que a maioria de nossos(as) respondentes tenha declarado pertencimento aos quadros docentes e discentes de universidades nacionais, a pluralidade das demais respostas impede a produção de mais generalizações. No Anexo I apresentamos os números brutos e as proporções de estudantes e professores de instituições de pós-graduação do país. Esses dados nos auxiliam a ter uma noção da extensão da comunidade de cientistas sociais no Brasil, enquanto os resultados do questionário apresentam indícios importantes para o desenvolvimento de novas pesquisas sobre as consequências da pandemia nas atividades de trabalho acadêmico, a partir de um retrato parcial desse perfil de trabalhadores(as).

As perguntas buscaram avaliar aspectos particulares da organização das atividades acadêmicas em meio às novas formas de socialização que surgiram com as medidas de isolamento social. Para tal, separamos o questionário em duas ênfases, uma voltada para as características pessoais dos(as) respondentes e outra direcionada às práticas de trabalho. Para a dimensão de raça/cor, empregamos a autodeclaração racial baseada nas categorias utilizadas pelo Instituto Brasileiro de Geografia e Estatística (IBGE), ou seja, branca, amarela, indígena, preta ou parda, além das opções outra e NR, para quem preferisse não responder. O gênero, como atributo socialmente construído, foi mensurado a partir das alternativas feminino, masculino, outro e NR.

\section{RESULTADOS}

\section{Perfil dos(as) respondentes}

As grandes áreas das ciências sociais tiveram trajetórias de institucionalização e expansão diferenciadas no Brasil. A ciência política e as relações internacionais (CP\&RI), que nas avaliações da Coordenação de Aperfeiçoamento de Pessoal de Ensino Superior (Capes) são consideradas conjuntamente, somam o maior quadro de programas de pós-graduação (profissionais e acadêmicos), seguidas da sociologia e da antropologia. ${ }^{3}$ Essa informação é relevante para a comparação entre o conjunto de respostas que tivemos e a composição das disciplinas que desejamos observar. No que toca aos campos de concentração de trabalho, o corpus da pesquisa reproduziu igual ordenação quantitativa dos 
programas de pós: em primeiro lugar, foi mais numerosa a participação dos profissionais da ciência política $(n=274)$ e das relações internacionais $(n=182)$, que juntos totalizaram 456 pessoas ou $43 \%$ da amostra. Em seguida, a sociologia contou com 334 respondentes e perfez 3 I\% dos grupos analisados. A antropologia, por sua vez, atingiu 232 respondentes, correspondendo a $22 \%$; e, por fim, o rótulo outros agrupou $5 \%$ do total, 5 I casos provenientes de 2 I disciplinas diferentes das humanidades.

Para o quesito local de residência, o paralelo com a presença de instituições de formação e pesquisa também é possível. Em ordem decrescente, os/ as respondentes da pesquisa declararam domicílio no Sudeste $(49 \%)$, Nordeste (I $8 \%$ ), Sul (I7\%), Centro-oeste (I0\%) e Norte (5\%), o que representa padrão similar ao da distribuição dos programas de pós-graduação nas grandes áreas das ciências sociais pelo país, ${ }^{4}$ ainda bastante desigual. Os casos de moradia no exterior foram minoritários (2\%). A maioria desses(as) respondentes é composta de doutores(as) (47\%), doutorandos(as) (24\%) ou mestrandos(as) (I5\%), com parcela diminuta de mestres(as) (8\%) e graduados(as) (6\%). Associa-se a esses dados a predominância de indivíduos que afirmaram vínculo de trabalho no meio acadêmico, fator que é condizente com o público-alvo que este estudo buscou alcançar. A Tabela I apresenta as principais ocupações que cada participante declarou em uma pergunta com múltiplas respostas, cuja totalidade pode ser consultada no Anexo 2 deste artigo. Dominam entre os/as respondentes as atividades docentes e discentes de pós-graduação, apesar de muitos(as) também indicarem outras atividades acadêmicas dispersas, aqui agrupadas na categoria outros.

\begin{tabular}{l|c|c} 
Ocupação & N & $\%$ \\
Docente de universidade pública & 345 & 32,2 \\
\hline Estudante de pós-graduação bolsista & 275 & 25,6 \\
\hline Estudante de pós-graduação sem bolsa & I73 & I6, I \\
\hline Outras categorias* & 538 & 50,4 \\
Total & I.33I & -
\end{tabular}

Tabela I

Ocupação dos/as respondentes

$\mathrm{N}=$ I.073. Percentuais calculados em relação ao $\mathrm{N}$ e não às respostas, posto que se trata de variável de múltipla escolha.

* Há i7 categorias com menos de ı०\%. Para detalhamento, cf. a tabela completa no Anexo 2.

Fonte: as autoras com base em dados do survey

"O impacto da pandemia nas rotinas de trabalho acadêmico nas ciências sociais".**

** Aqui e em todos os gráficos, anexos e demais tabelas (em que essa informação não aparecerá) à exceção do Anexo I, cuja fonte está informada. 
Em relação à instituição de origem ou de atuação, 82\% dos(as) respondentes afirmaram vínculo com universidades públicas, I $\%$ com universidades privadas, e $6 \%$ manifestaram não se enquadrar em nenhuma das duas categorias. Mais uma vez, o resultado parece dar conta da conjuntura brasileira, em que as instituições públicas concentram grande parte dos programas de pós-graduação bem qualificados nas avaliações nacionais, assim como são as principais responsáveis por produtividade em pesquisas científicas. Vale mencionar que os/as respondentes do estudo pertenciam a pelo menos 5 I universidades, além de I4 casos com filiação a instituições estrangeiras.

As características dos(as) respondentes, de acordo com categorias socialmente construídas, mostraram severas assimetrias entre os grupos que constituem as comunidades das ciências sociais. Pretos(as) e pardos(as), parcela majoritária da população brasileira, frequentemente somados(as) em negros(as) pelo fato de partilhar condições socioeconômicas, ficaram subrepresentados(as) em todas as grandes áreas das humanidades que apareceram nos resultados do survey. Por outro lado, indígenas e amarelos(as) não chegaram a compor nem I\% do total analisado. Na Tabela 2 (na página seguinte) é possível constatar como cada perfil racial figurou entre os/as respondentes das disciplinas analisadas. Para facilitar a discussão que será apresentada a seguir, agrupamos as categorias parda, preta, amarela e indígena, além da resposta outra no rótulo não branco. Justificamos essa ação pela oposição dominante dos brancos, que são maioria mesmo diante da soma de todos os outros grupos raciais.

Essas desigualdades não constituem aspecto particular à demografia dos(as) respondentes de nosso questionário. Em um estudo sobre diversidade nas ciências sociais, que se restringiu à análise de professores(as) de pós-graduações, a assimetria entre brancos(as) e o somatório de pretos(as) e pardos(as) se mostrou ainda mais profunda (Candido, Feres \& Campos, 20I9). A presença considerável de estudantes que ainda não desfrutam de posição estável no mercado de trabalho pode ser um diferencial que pesa para a maior representatividade de pessoas pretas e pardas entre os/as participantes do survey, quando comparadas a suas baixas proporções nos quadros docentes.

O mesmo não necessariamente é válido para a distribuição de gênero na amostra. A presença de estudantes pode ter influenciado a maior parcela feminina no total de respondentes mesmo em áreas nas quais elas são minoritárias como professoras na pós-graduação, tais quais a ciência política e a sociologia (Candido, Feres \& Campos, 20I9). Nota-se, como apresentado no Gráfico I (na página seguinte), que mesmo no caso das mulheres não brancas, severamente sub-representadas como docentes em todas as disciplinas que analisamos, há significativa proporção de participantes, que chega a exceder os respondentes homens brancos na sociologia. 


\begin{tabular}{|c|c|c|c|c|c|c|}
\hline $\begin{array}{l}\text { Raça/ } \\
\text { Área CS }\end{array}$ & Sociologia & $\begin{array}{l}\text { Ciência } \\
\text { política }\end{array}$ & Antropologia & $\begin{array}{l}\text { Relações } \\
\text { internacionais }\end{array}$ & $\begin{array}{l}\text { Outras } \\
\text { áreas }\end{array}$ & $\begin{array}{l}\text { Total da } \\
\text { amostra }\end{array}$ \\
\hline Branca & 62 & $7 \mathrm{I}, 9$ & 72,8 & 76,4 & 68,6 & 69,6 \\
\hline Parda & 22,2 & I 8,2 & I5,5 & $\mathrm{I} 4,3$ & 23,5 & I 8,5 \\
\hline Preta & I3,8 & 8,8 & 7,3 & 5,5 & 3,9 & 9,2 \\
\hline Amarela & $\mathrm{I}, 2$ & 0,7 & 0,9 & - & 3,9 & 0,9 \\
\hline Indígena & - & - & 0,9 & - & - & 0,2 \\
\hline Total & 100 & I00 & I00 & I00 & I00 & I00 \\
\hline $\mathrm{N}$ & $33 I$ & 273 & 226 & 175 & $5 I$ & I.056 \\
\hline
\end{tabular}

Tabela 2

Raça dos(as) respondentes por área das ciências sociais (\%)

$\mathrm{N}=\mathrm{I} .056$ (foram excluídas as não respostas/outras raças).

Essas desigualdades não constituem aspecto particular à demografia dos(as) respondentes de nosso questionário. Em um estudo sobre diversidade nas ciências sociais, que se restringiu à análise de professores(as) de pós-graduações, a assimetria entre brancos(as) e o somatório de pretos(as) e pardos(as) se mostrou ainda mais profunda (Candido, Feres \& Campos, 2019). A presença considerável de estudantes que ainda não desfrutam de posição estável no mercado de trabalho pode ser um diferencial que pesa para a maior representatividade de pessoas pretas e pardas entre os/as participantes do survey, quando comparadas a suas baixas proporções nos quadros docentes.

60

51 48 49

50 42 $4 \mathrm{I}$

40

30

20

TI"

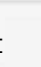

3 I 28

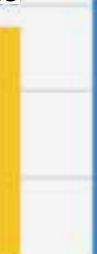

O

Sociologia

$$
\begin{aligned}
& \text { Ciência } \\
& \text { política }
\end{aligned}
$$

\section{Antropologia}

22

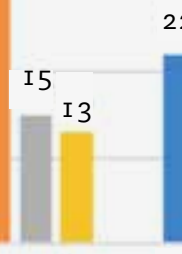

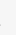

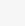

- Antropologia

\section{Relações} internacionais

29

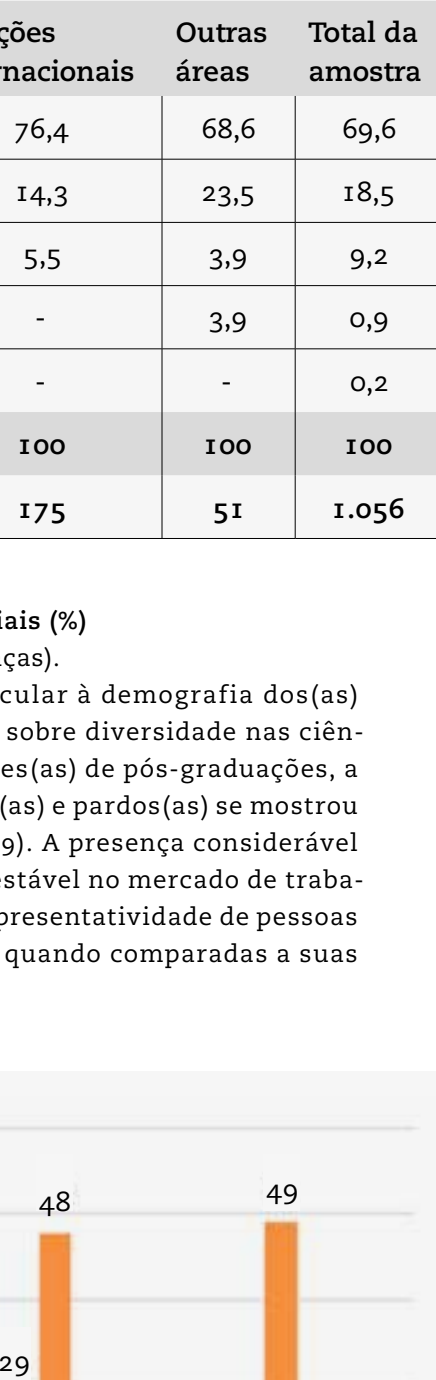

homem branco wn mulher branca homem não branco * mulher não branca

\section{Gráfico I}

Raça e gênero dos(as) respondentes por grande área das ciências sociais (\%) $\mathrm{N}=\mathrm{I} .073$ (foram excluídas as não respostas). 
As últimas duas informações que desejamos destacar sobre o perfil social dos respondentes dizem respeito à faixa etária e ao número de filhos(as). Foram mais recorrentes na amostra as idades de 25 a 34 anos (40\%) e de 35 a 44 anos (29\%), seguidas pelas faixas de 45 a 54 anos (I $3 \%)$, de i 8 a 24 anos (8\%), de 55 a 64 anos (7\%) e de 65 anos ou mais (4\%). Embora tenham sido majoritárias as faixas etárias que concentram a maior parte do período reprodutivo, o percentual de respondentes com filhos(as) em nosso estudo não foi alto. Pelo contrário, $65 \%$ dos(as) participantes declararam não ter crianças. O dado é relevante principalmente por duas razões: em primeiro lugar, sugere uma baixa taxa de natalidade entre acadêmicos(as) das ciências sociais, que pode ser ponderada pela diferença de estágios de progressão de carreira. Conforme veremos no restante dos resultados apresentados, a proporção de cientistas sociais da amostra que são mães ou pais é maior entre pessoas com doutorado: dos(as) I.073 respondentes, $356(33,2 \%)$ têm filhos(as), sendo que $66,4 \%$ dessa parcela é formada por doutores(as). Dos(as) doutores(as), 52,7\% têm filhos(as), enquanto a quantidade de respondentes não chega a $30 \%$ em nenhuma das outras titulações anteriores, e a menor frequência, 2 I,3\%, é entre doutorandos(as).

Em segundo lugar, o dado também ressalta a necessidade de os estudos sobre desigualdades na composição dessas disciplinas darem mais preponderância à divisão sexual do trabalho, que não se reduz somente à questão da maternidade (Biroli, 20I6). Muitas pesquisas têm contribuído para demonstrar que as mulheres mães são penalizadas por sistemas de avaliação de produtividade que não consideram a licença maternidade, nem o cuidado com as crianças (Staniscuaski et al., 2020). Há também, no entanto, outros aspectos de organização da vida doméstica e da família que tornam mais oneroso o desenvolvimento de carreira para o gênero feminino - assim como pode haver mesmo um modo de organização da vida acadêmica que imponha a escolha entre ela e a maternidade (Castro \& Chaguri, 2020).

\section{IMPACTO DA PANDEMIA NAS ROTINAS DE TRABALHO ACADÊMICO} Impacto na rotina de trabalho

Embora a maioria dos(as) participantes do survey tenha relatado que a pandemia impactou negativamente suas rotinas de trabalho acadêmico, os resultados referentes aos/às mais afetados(as) variaram conforme os perfis sociais de gênero e raça, como mostra o Gráfico 2 (na página seguinte). Pessoas autodeclaradas pretas, pardas, amarelas e indígenas, agrupadas na categoria não brancos(as), são as que mais indicaram a opção "muito negativamente" para qualificar as consequências da covid-I9 - 29\% tanto de homens quanto de mulheres optaram por tal item. Entre a pequena parcela que declarou consequências positivas, por sua vez, esse grupo também foi mais recorrente, sendo I०\% tanto para homens quanto para mulheres. 


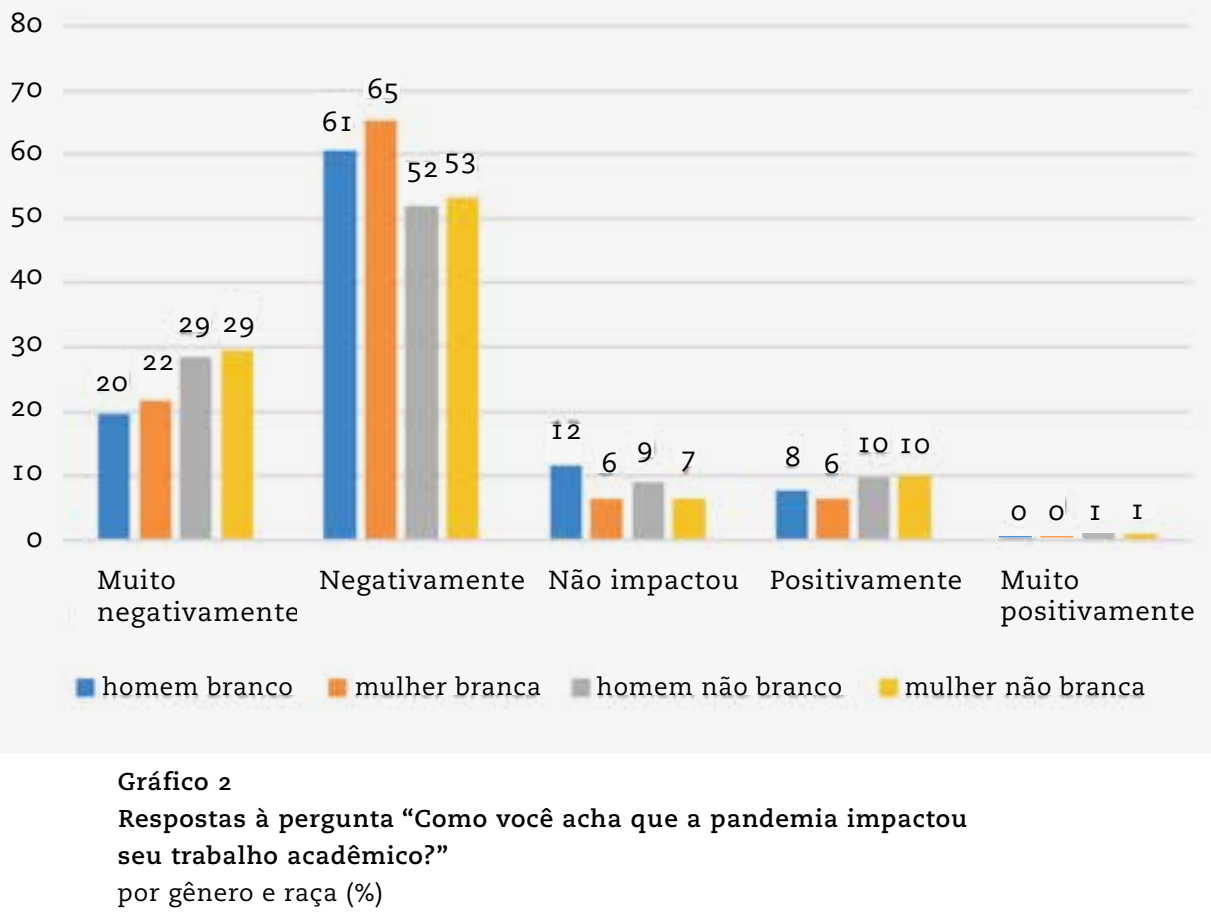

A percepção generalizada de que a pandemia prejudicou o trabalho de cientistas sociais brasileiros(as) se alinha com a pesquisa de Marijke Breuning et al. (2020), que encontrou igual resultado para cientistas políticos(as), em sua maioria, estadunidenses. Nossos dados, tal como os de Breuning et al., mostram que homens e mulheres relatam impactos negativos da covid-Ig em sua vida profissional. No trabalho das autoras, no entanto, as diferenças de gênero só puderem ser mais evidenciadas a partir do conteúdo das questões abertas, nas quais o grupo feminino acabou descrevendo detalhes de sobrecarga nas atividades da esfera privada. Mais à frente, demonstramos oscilações que apareceram em nossas questões fechadas, especialmente no que toca ao uso do tempo.

Em termos de estágios da carreira acadêmica, também não houve diferença no predomínio geral das respostas: em todos os casos a percepção de que a pandemia foi negativa para as rotinas de trabalho é dominante. Há, contudo, leve oscilação na frequência dos(as) que consideraram os impactos "muito negativos". Essa opção foi mais recorrente entre os/as pós-graduandos(as), sendo 36\% das respostas de mestrandos(as) e $25 \%$ das escolhas dos(as) doutorandos(as) - o que é compreensível, considerando o tempo mais curto para a conclusão do mestrado, a instabilidade inicial das posições dos programas de pós quanto às estratégias 
de continuidade das aulas e dos prazos, bem como a insegurança que rege os/as estudantes no tocante à duração de bolsas de pesquisa. Os/as graduados(as) vieram logo em seguida, com 23\%, os/as mestres(as) com $22 \%$, e os/as doutores(as), com I $8 \%$. Este último grupo foi o que mais declarou ter sentido impacto positivo, tendo totalizado Io\% nessa resposta, resultado que se aproxima apenas dos referentes a graduados(as), com $9 \%$. Doutorandos(as), mestres(as) e graduandos(as) quase não qualificaram os efeitos da pandemia em sua rotina de trabalho acadêmico como algo positivo. Fato é que a soma daqueles(as) que consideram que a pandemia afetou "muito negativamente" ou "negativamente" é alta entre todos(as) os/as respondentes das categorias mencionadas. Os totais chegam a valores superiores a $80 \%$, sendo que superam os $90 \%$ no caso dos(as) mestrandos(as) e ficam próximo a isso entre os/as doutorandos(as).

A Tabela 3 apresenta os principais impactos da pandemia nas rotinas de trabalho dos(as) acadêmicos(as) respondentes. A covid-I9 e o isolamento social afetaram o trabalho dos(as) cientistas sociais, em primeiro lugar, em função do aumento do dispêndio de tempo com o cuidado da casa e/ou de familiares (6I\%). A desorganização na rotina provocada pela pandemia foi demarcada como um empecilho ao cumprimento de prazos de $44 \%$ dos(as) entrevistados(as) e também gerou incertezas em relação ao futuro para $38 \%$. Além de incremento nas tarefas domésticas, foi relatado aumento nas demandas de trabalho acadêmico $(35 \%)$ e administrativo (24\%).

As demais consequências percebidas pelos(as) cientistas, em geral, se referiram a incertezas em relação a seu planejamento da carreira ou indicaram alterações custosas nos cronogramas e nas práticas usuais de trabalho. A Tabela 3 mostra as respostas mais recorrentes, indicadas por mais de $20 \%$ dos(as) respondentes.

\begin{tabular}{l|c} 
Impacto da pandemia no trabalho & $\%$ \\
\hline $\begin{array}{l}\text { A pandemia prejudicou minha organização para trabalhar, } \\
\text { pois gasto mais tempo cuidando da casa e/ou da família }\end{array}$ & 6 I \\
\hline $\begin{array}{l}\text { A pandemia provavelmente me fará não cumprir prazos, } \\
\text { porque afetou globalmente minha organização do trabalho }\end{array}$ & 44 \\
\hline $\begin{array}{l}\text { A pandemia mudou minhas perspectivas de futuro, } \\
\text { pois não sei como serão os prazos da pós-graduação }\end{array}$ & 38 \\
\hline A pandemia aumentou minhas demandas de trabalho acadêmico & 35 \\
\hline A pandemia adiou concursos públicos que eu ia tentar & 25 \\
\hline A pandemia aumentou minhas demandas de trabalho administrativo & 24 \\
\hline
\end{tabular}

Tabela 3

Principais impactos da pandemia nas rotinas de trabalho

$\mathrm{N}=\mathrm{I} .073$. 
Poucos(as) respondentes ${ }^{5}$ disseram ter contraído a covid- $19,{ }^{6}$ e alguns/ algumas não se identificaram com as opções elencadas pelo questionário, tendo espontaneamente manifestado efeitos negativos em termos de saúde mental no espaço para respostas abertas. Como se pode constatar, para os/as participantes da pesquisa a pandemia não representou ganhos nos modos de organização da vida social. O único fator que pode ser lido como ambivalente trata do apontamento de que o tempo para escrever artigos melhorou para i $2 \%$ dos(as) respondentes.

A observação desse mesmo dado cruzado com gênero e raça mostra variações que devem ser ressaltadas, como indicado no Gráfico 3 (na página seguinte). As mulheres têm suas rotinas de trabalho significativamente mais afetadas pela pandemia e percebem um aumento das demandas acadêmicas de maneira mais intensa do que os homens brancos. As mulheres brancas, por seu turno, relatam sentir mais os efeitos da covid-Ig em relação a questões de cuidado do que as mulheres não brancas, ainda que a diferença entre elas seja pequena. Sobre a rotina de trabalho acadêmico daqueles(as) que ainda estão na pós-graduação ou já a terminaram, mas não estão inseridos(as) no mercado de trabalho, as mudanças com a chegada do novo coronavírus afetaram sobremaneira as perspectivas das mulheres não brancas: quase metade respondeu que sentiu impacto nas percepções sobre o futuro.

Os homens não brancos oscilaram no padrão de respostas. Ora se aproximaram das mulheres brancas e não brancas, ora dos homens brancos. O que mais sobressai, todavia, é a tendência apresentada pelos homens brancos: eles foram os que menos sentiram alteração nas demandas de trabalho, os que mais tiveram estágios no exterior interrompidos e, especialmente, os que mais consideraram que a pandemia melhorou o tempo para a produção de artigos, pois não era necessário dar aulas. Enquanto esta última opção representou I8\% das escolhas dos homens brancos, ela foi de i I\% para mulheres brancas e homens não brancos, e de $7 \%$ para mulheres não brancas. Vale salientar, no entanto, que esse quadro pode ser distinto agora, no segundo ano da pandemia, quando muitas universidades retomaram suas aulas pelo modo remoto. No momento em que o survey foi aplicado, a maior parte delas estava com as aulas suspensas. 
Trabalho prejudicado por questões de cuidado

Provavelmente prazos serão descumpridos

Mudanças nas perspectivas de futuro, por incertezas de cronogramas na pós-graduação

Aumento das

demandas

de trabalho acadêmico

Adiamento de oportunidades em concursos públicos

Aumento das demandas de trabalho administrativo

Prejuízo a oportunidades de entrada no mercado de trabalho na iniciativa privada

Perda de

trabalhos

remunerados

Manutenção das mesmas demandas de trabalho, pois as aulas seguem online e o trabalho remoto

Melhoria de tempo para produção de artigos, pois não necessita mais dar aulas Interrupção de estágios de pesquisa em instituições estrangeiras

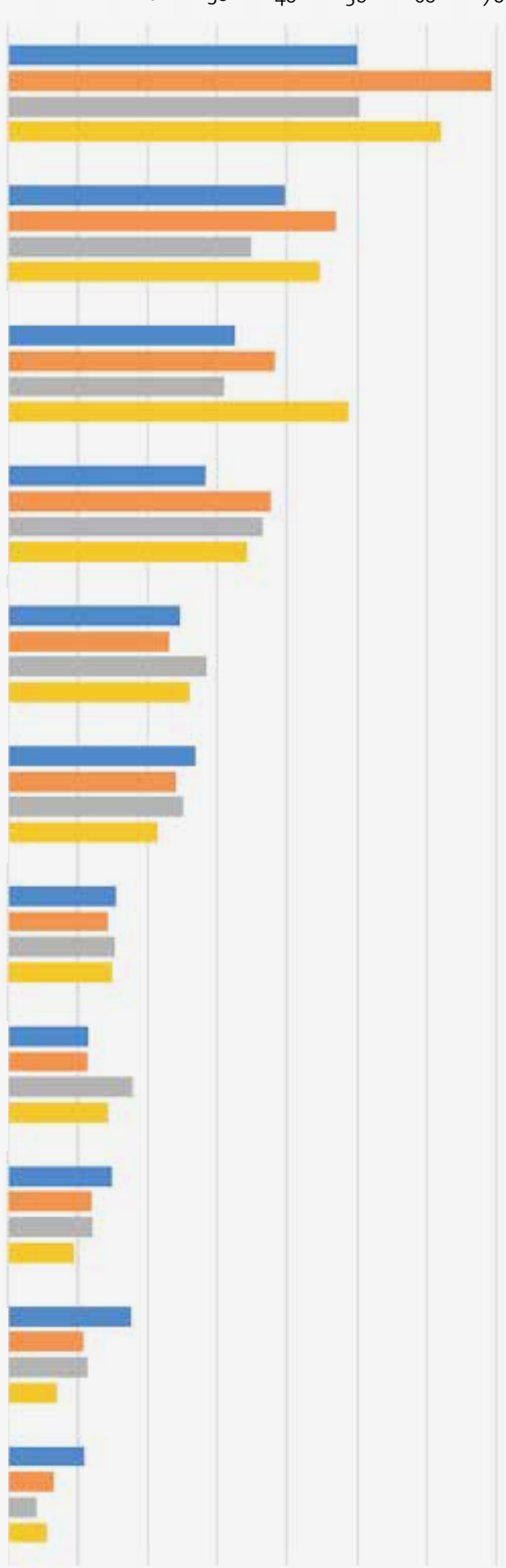

80

homem branco

mulher branca

homem não branco

mulher não branca

\section{Gráfico 3}

Itens mais indicados sobre as rotinas de trabalho acadêmico durante a pandemia de acordo com gênero e raça (\%) 


\section{Impacto nas pesquisas}

A pandemia e o isolamento social prejudicaram as técnicas de pesquisa de $51 \%$ dos(as) respondentes. Mas isso se deu de maneira variável, segundo a área e os métodos investigativos adotados. A antropologia foi a disciplina mais afetada, com $79 \%$ dos(as) pesquisadores(as) indicando ter tido problemas para dar continuidade a suas pesquisas, seguida das outras áreas (6I\%), da sociologia (58\%), da ciência política (38\%) e das relações internacionais (2 I \%). Para a parcela que manifestou tal problema, o questionário instituiu uma seção aberta para sinalizar quais métodos específicos tinham sido impossibilitados. Deles, os mais recorrentes foram: entrevistas (2 I \%), pesquisa de campo (I $3 \%$ ), etnografia (I I \%), observação participante (I0\%), grupos focais ( $3 \%$ ), pesquisa em acervos $(2 \%)$ e aplicação de questionários ( $2 \%)$. O restante variou enormemente, e não chegou a atingir, cada um, I\% da amostra.

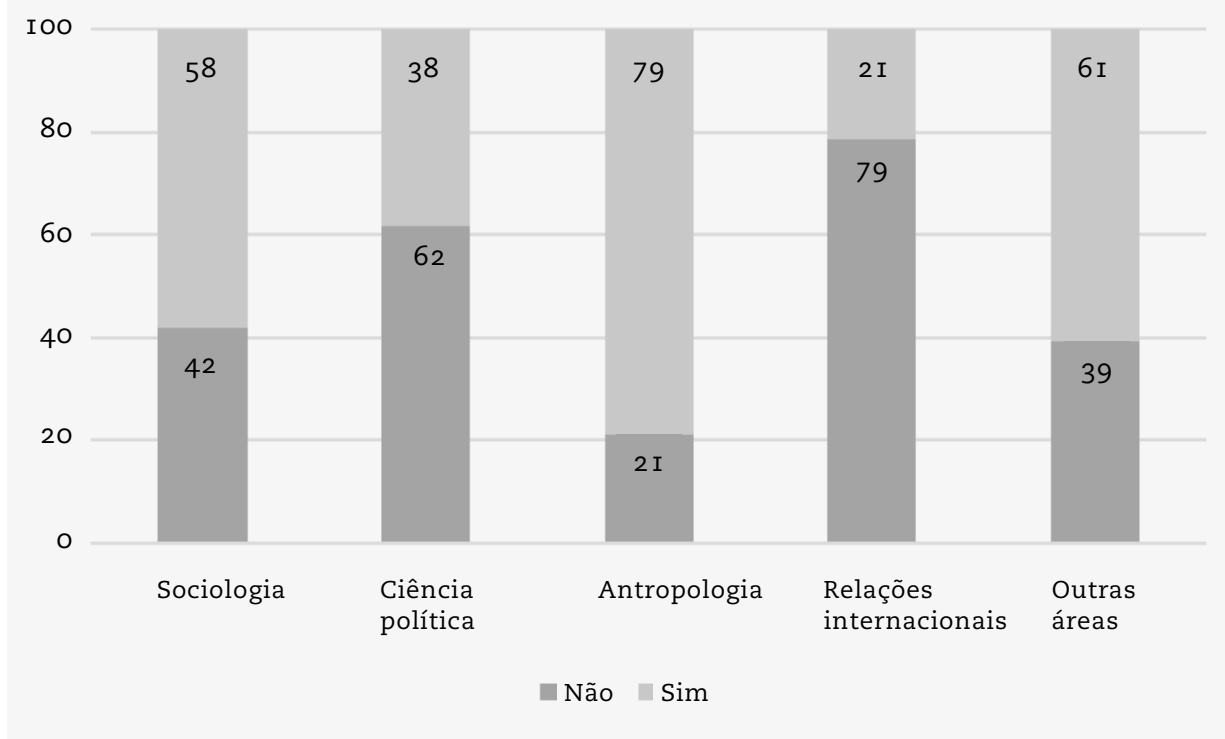

Gráfico 4

Pandemia e problemas com técnicas de pesquisa em grandes áreas das ciências sociais (\%) 


\section{Impacto na produtividade}

A produtividade foi afetada de maneira variável, de acordo com gênero e raça. Tal quesito foi analisado por um conjunto de atividades que compõem o cotidiano de trabalho dos(as) pesquisadores(as), entre elas: produção de artigo científico e resenha, livro ou capítulo de livro, texto em meios de comunicação voltados para o grande público, editoração, produção de pareceres etc. Quando consideramos a produção de artigos científicos, que é um aspecto central da carreira de pesquisadores(as) e da avaliação dos programas de pós-graduação, as mulheres não brancas apresentam proporções menores de produtividade do que os demais grupos (32\%), ao passo que os homens brancos apresentaram os maiores níveis de produção (42\%). Isso se repete quando são considerados capítulos de livros e ensaios em jornais ou revistas. São as mulheres não brancas, também, que apresentam a maior incidência de respostas indicando que não produziram no período, seguidas pelas mulheres brancas, como se pode ver no Gráfico 5 .

60

50

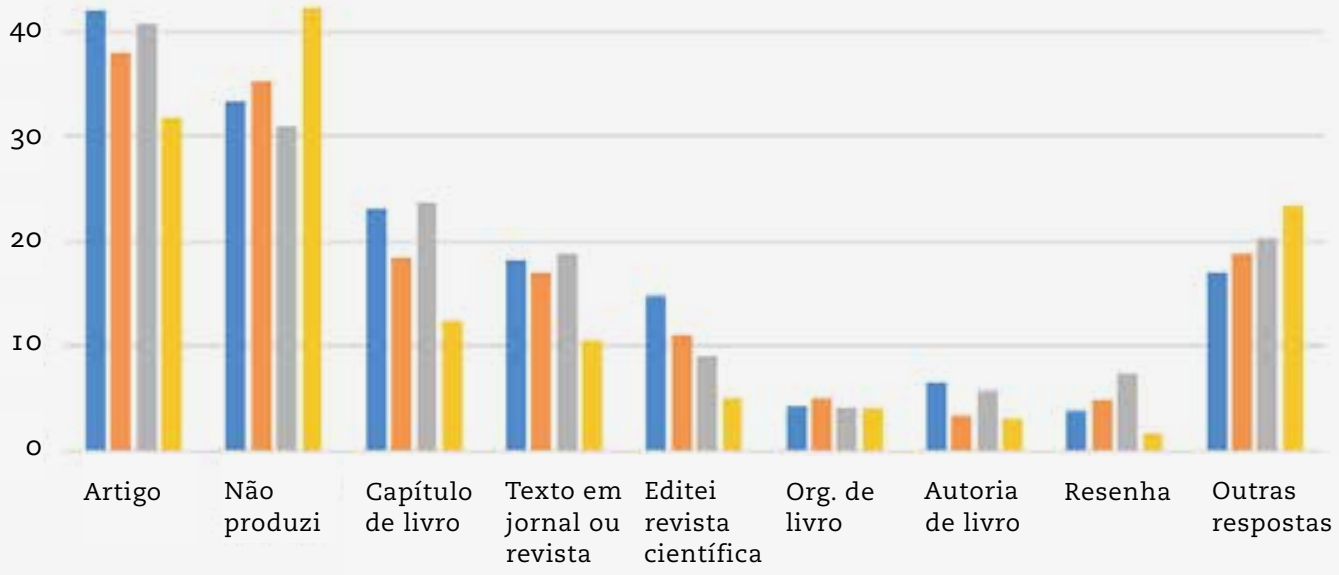

" homem branco $\|$ mulher branca " homem não branco $=$ mulher não branca 
A pesquisa também comparou respondentes com ou sem filhos(as), e os dados mostram que a produtividade dos(as) respondentes que têm filhos(as) é, em média, maior do que aquela do conjunto de respondentes que não têm filhos(as) ou não indicou se é pai ou mãe. A submissão de artigos de respondentes que têm filhos(as) foi de $4 \mathrm{I} \%$, e a de pessoas sem filhos(as), de $36 \%$. Por outro lado, entre as pessoas que têm filhos(as), 33\% afirmaram não ter produzido nada no período, enquanto respondentes com filhos(as) indicaram um percentual maior, de $37 \%$. Esses resultados poderiam refletir a idade e o patamar de carreira dos(as) respondentes. Assim, controlamos o impacto da pandemia na produtividade pela atividade de cuidado de crianças (e não apenas ser pai ou mãe) e também de cuidado de idosos. Essa análise mostra que há de fato impacto negativo do trabalho de cuidado de dependentes durante a pandemia na produtividade, como se vê no Gráfico 6.

\section{0}

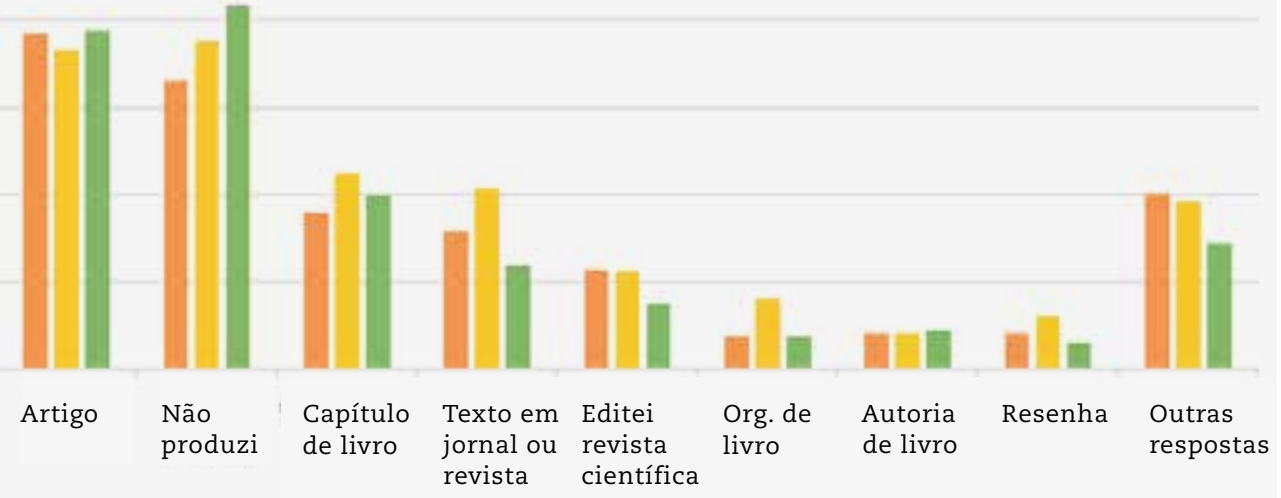

= Não cuida de ninguém $=$ Cuida de filho/a =Cuida de idoso/a(s) 
A distribuição dos tipos de produção varia bastante, mas é importante notar que as pessoas que cuidam de idosos são aquelas que mais indicaram que não produziram nada no período (4I,9\%), diferentemente das pessoas que não exercem atividades de cuidado $(33,2 \%)$.

Entre docentes de universidades públicas e privadas, que constituem 40,8\% de nossa amostra e 59,6\% dos(as) respondentes com filhos(as), embora os dados apontem algumas diferenças entre quem exerce cuidado e quem não exerce, não é possível afirmar que haja uma relação estatisticamente significativa entre cuidar de crianças ou idosos(as) e um efeito negativo na produtividade (Gráfico 7). A pressão sobre os/as docentes para que mantenham níveis de produtividade altos talvez chegue a ter outros efeitos, como a estafa, em momento no qual o trabalho doméstico e de cuidado se ampliou. No grupo de docentes, $73,8 \%$ indicaram aumento do trabalho doméstico, o que se eleva para $80,5 \%$ no caso dos docentes que cuidam de filhos(as). $O$ acesso a lazer é que parece ser mais impactado nesse caso, segundo dados que serão apresentados mais adiante.

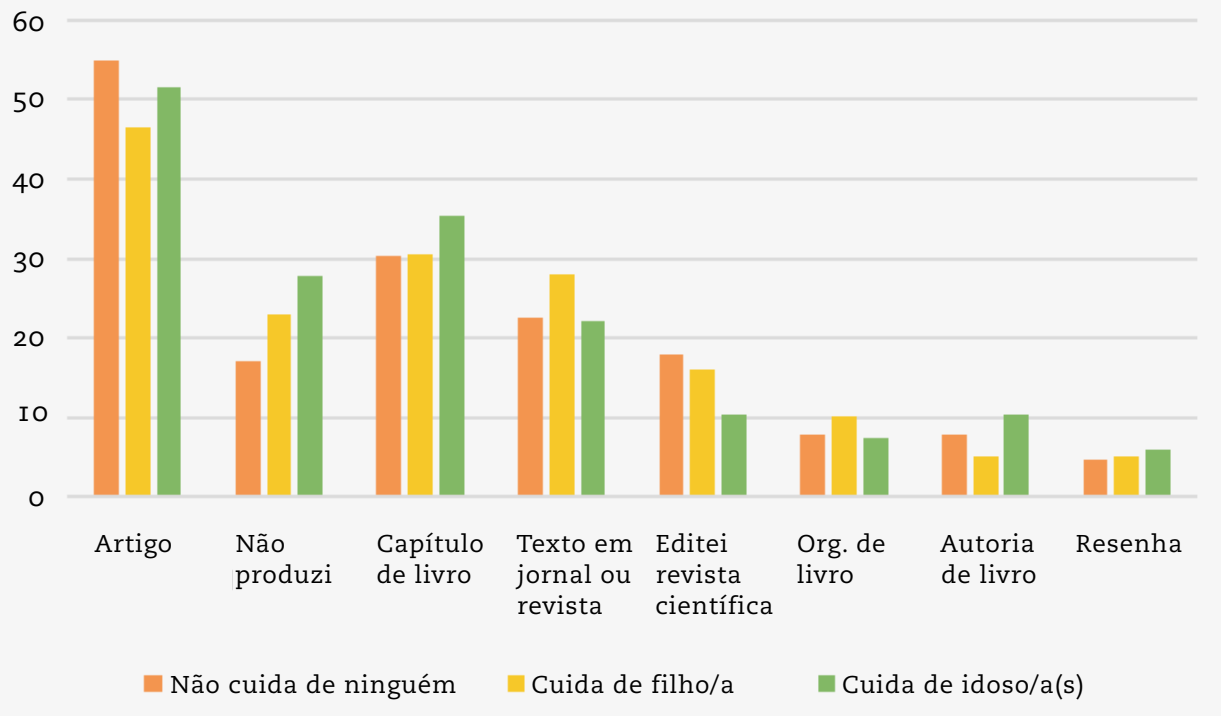

Gráfico 7

Pandemia, produtividade e cuidado entre os/as respondentes docentes (\%) 
O impacto negativo do cuidado de crianças e idosos(as) na pandemia tem efeito mais presente entre respondentes que não são docentes (o que concentra principalmente pós-graduandos(as), que são 33,7\% da amostra e metade dos casos de não docentes entre os/as respondentes). Entre eles(as), a principal categoria indicada é "não produzi nada nesse período de pandemia", sendo marcante a distância entre as pessoas que exercem tarefas de cuidado e as que não cuidam de alguém, como se percebe no Gráfico 8.

Uma importante observação é que, quando controlamos os dados pela área de atuação nas ciências sociais, não identificamos variação entre elas. Assim, pode-se dizer que o trabalho de cuidado afeta cientistas sociais de todas as áreas, sendo o efeito negativo na produção acadêmica mais presente entre os/as respondentes que não são docentes de universidades públicas e privadas. De todo modo, também é relevante ponderar que a pressão por produtividade é diferenciada entre estudantes e professores(as). Mesmo que os/as discentes precisem construir um currículo para conquistar oportunidades profissionais, não estão sujeitos(as) às demandas exigidas dos(as) docentes, que são avaliados(as) por agências de fomento.

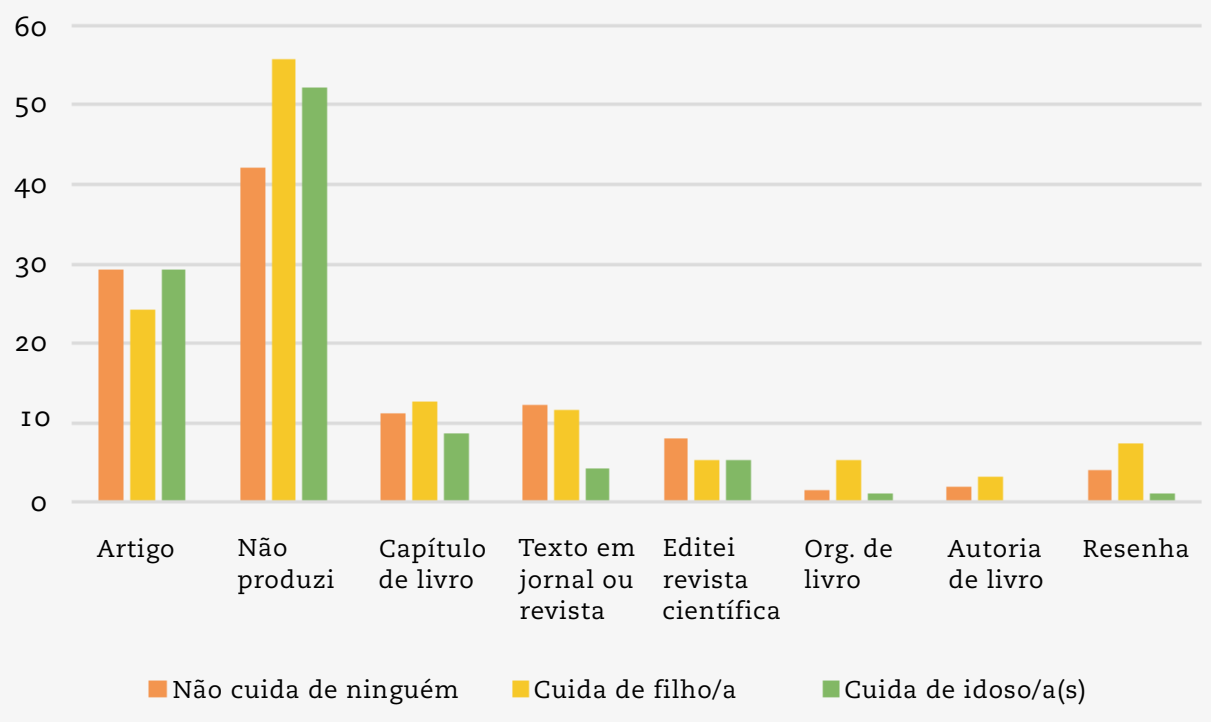




\section{IMPACTO DA PANDEMIA NAS TAREFAS DOMÉSTICAS E DE CUIDADO Impacto na rotina doméstica}

Entre os/as respondentes, há a percepção geral de que o trabalho em casa é pior, não importa o pertencimento de raça/cor ou gênero. A taxa que avalia negativamente o trabalho em casa é de $63 \%$ para homens e $65 \%$ para mulheres; de $65 \%$ entre brancos(as) e $62 \%$ entre não brancos(as).

Há um relato comum de maior cansaço, em função dos longos períodos em frente ao computador, na rotina dos(as) pesquisadores(as) das ciências sociais na pandemia. Da mesma forma, esses profissionais declaram dificuldade para organizar o tempo - em média, 50\% apresentam tal percepção. Quando o dado é controlado por gênero, uma diferença importante reaparece aqui: a questão do cuidado. Mulheres brancas e não brancas indicam maior dispêndio de tempo para atividades de cuidado do que os homens, e a desigualdade é significativa, conforme indicam os dados do Gráfico 9 (na página seguinte).

Em oposição àqueles(as) que consideram o trabalho em casa pior, um pouco mais de $20 \%$ afirmaram que "se concentram melhor em casa" e/ou que "a estrutura da minha casa é melhor para trabalhar". Em porcentagem um pouco inferior, pesquisadores(as) manifestaram que organizam melhor o seu tempo com o trabalho. Mais de $30 \%$ declararam que economizam o tempo do trânsito e, portanto, podem trabalhar mais. Homens relatam mais do que mulheres o fato de que o trabalho em domicílio durante a pandemia é bom, pois possibilita passar mais tempo com os/as filhos(as). Possivelmente, os homens estavam mais fora de casa do que as mulheres antes da difusão do novo coronavírus e por isso percebem de maneira distinta a possibilidade de estar mais tempo com os/as filhos(as).

A desigualdade do impacto da covid-ı 9 na rotina doméstica aumenta quando comparamos respondentes com ou sem filhos, sobretudo em três aspectos: o trabalho doméstico aumenta mais para os/as cientistas sociais com filhos(as) (73\%) do que para quem não os/as têm (64\%); como era de esperar, pais e mães gastam muito mais tempo com atividades de cuidado (53\%) do que quem não tem filhos(as); e o cuidado com os/as filhos(as) dificulta a concentração para $47 \%$ dos(as) respondentes.

A necessidade de cuidados com os/as filhos(as) é maior para quem tem crianças pequenas, e o tempo gasto com o cuidado tende a diminuir com crianças maiores ou adolescentes. Pesquisadores(as) em estágios mais avançados da carreira podem ser, assim, menos afetados(as), na pandemia, pelo tempo gasto com os cuidados de filhos(as) ou pelas dificuldades de concentração. 


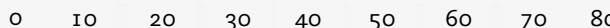

Aumento do

trabalho

doméstico

Cansaço

por causa

das telas

Dificuldade

de organização

do tempo

Aumento

das atividades

de cuidado

Falta de

concentração

Filhos(as)

dificultam a

concentração

Falta de

estrutura de

trabalho

Economia de tempo no trânsito,

o que permite

trabalhar mais

Melhora a

concentração

Melhora a

estrutura para

trabalhar

Melhora a

produtividade

Melhora a

organização

do tempo

É bom ter mais

tempo com

os/as filhos/as

Nenhuma das afirmações

acima
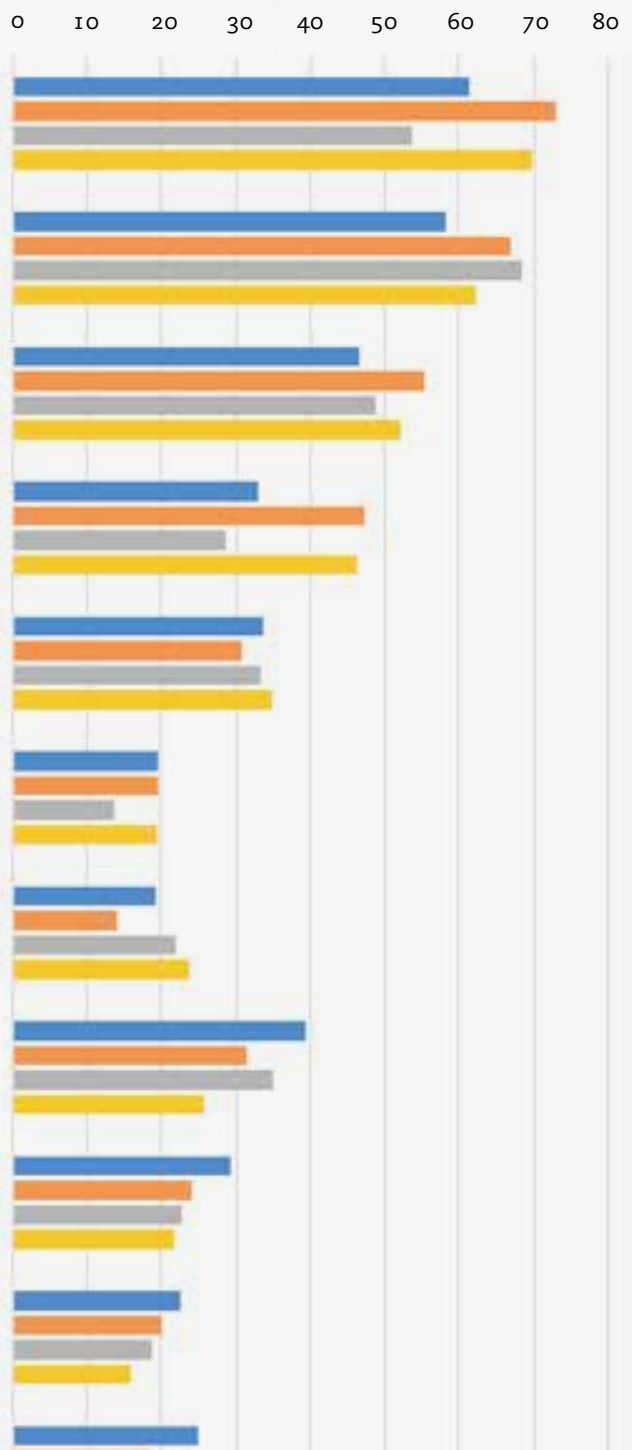

플
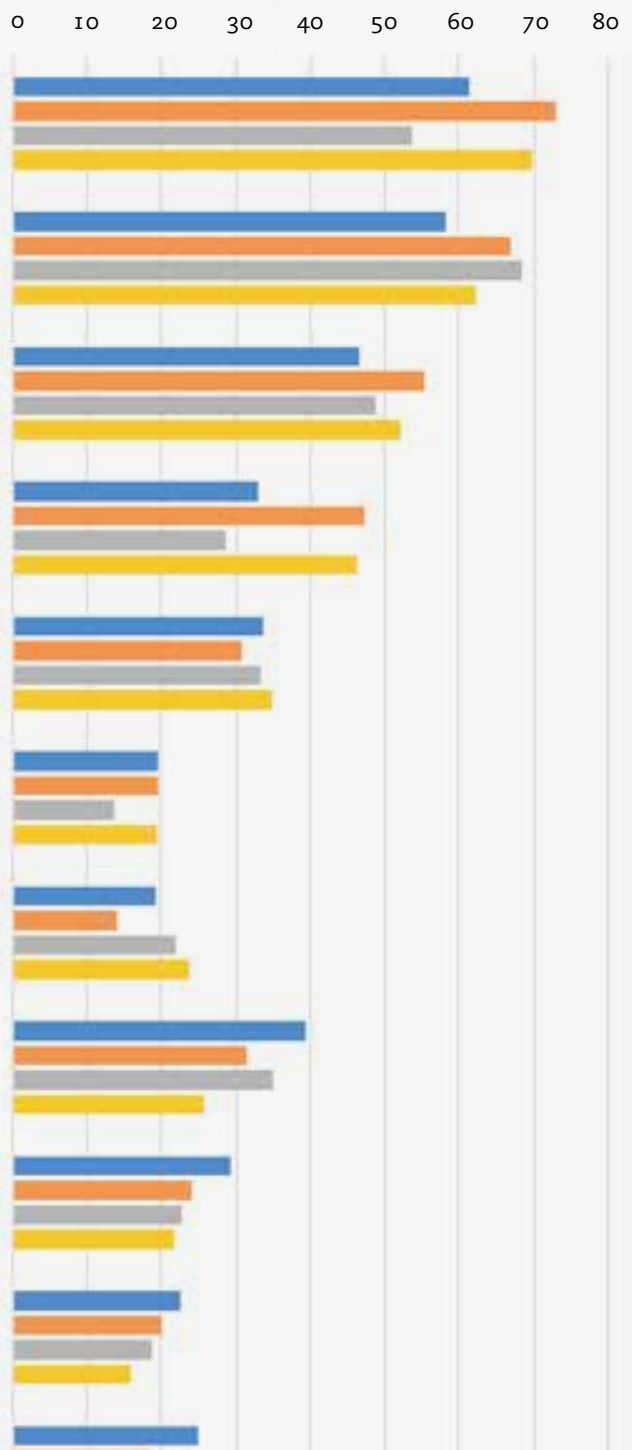

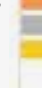
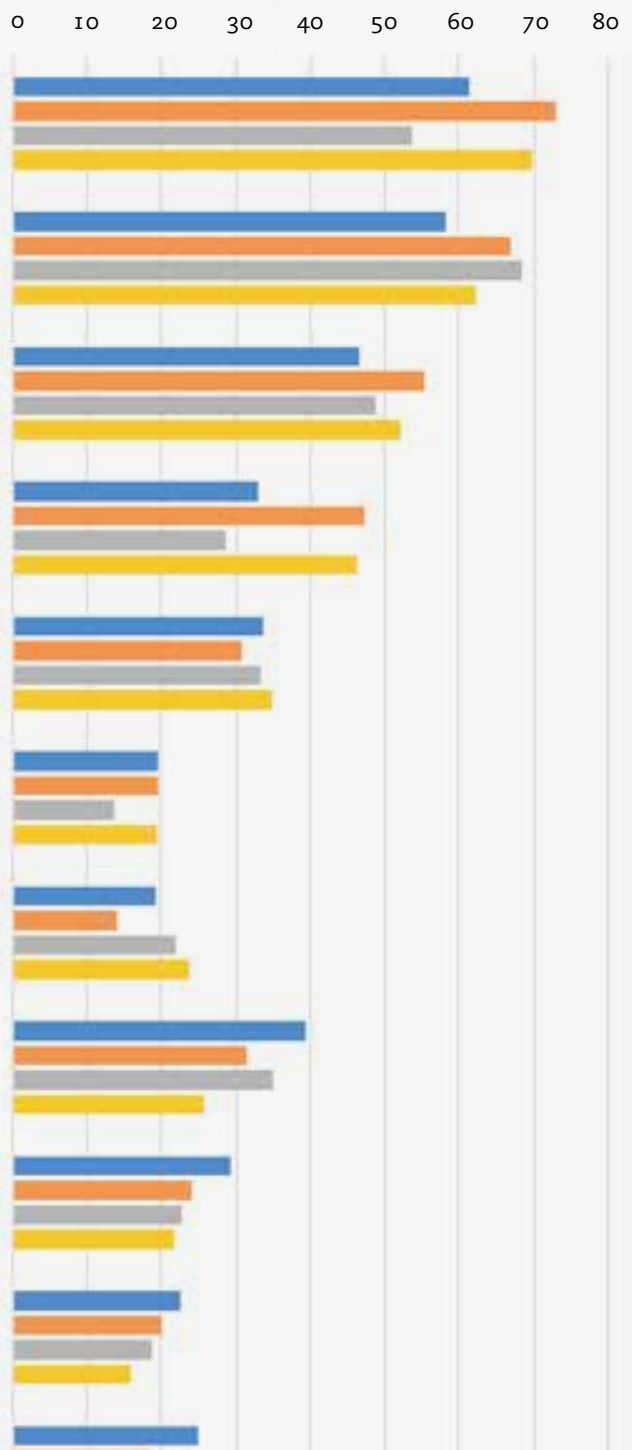

49 homem branco

mulher branca

homem não branco

mulher não branca

\section{Gráfico 9}

Itens mais indicados na avaliação do trabalho em casa de acordo com raça e gênero (\%) 
Aumento do

trabalho

doméstico

Cansaço

por causa

das telas

Dificuldade

de organização

do tempo

Aumento

das atividades

de cuidado

Falta de

concentração

Filhos(as)

dificultam a

concentração

Falta de

estrutura de

trabalho

Economia de

tempo no trânsito,

o que permite

trabalhar mais

Melhora a

concentração

Melhora a

estrutura para

trabalhar

Melhora a

produtividade
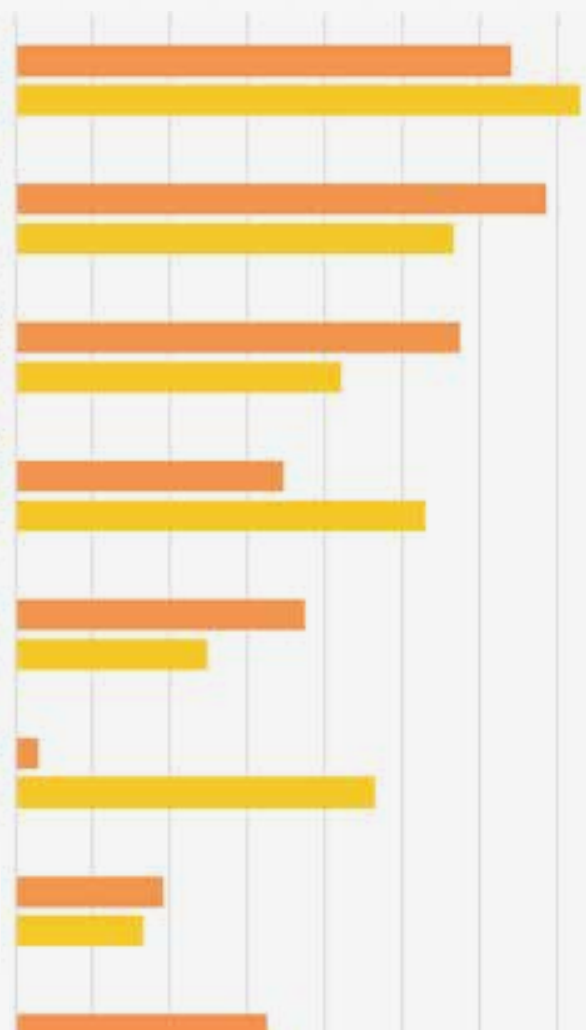

.

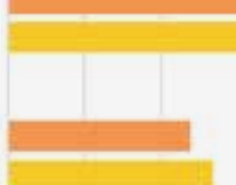

sem filhos(as)

afirmações

acima

\section{Gráfico Io}

Itens mais indicados na avaliação do trabalho de casa de acordo com as pessoas com e sem filhos(as) (\%) 
Os dados do Gráfico I I mostram que cientistas sociais gastam, em geral, até quatro horas diárias com tarefas domésticas. Homens gastam, em sua maioria, até duas horas, ao passo que as mulheres, brancas e não brancas, informam gastar entre três e quatro horas. Isso indica que as mulheres respondentes gastam, em média, o dobro das horas de trabalho doméstico do que os homens - dado que acompanha os achados das pesquisas de uso do tempo realizadas no país. Segundo o IBGE (2018), mulheres dedicam pouco mais do que o dobro de horas semanais ao trabalho doméstico (2 I,3 horas) do que homens (Io,9 horas). Chama a atenção o fato de que quase $20 \%$ das mulheres não brancas declararam gastar entre cinco e seis horas por dia com tarefas domésticas, o que com certeza impacta o tempo dedicado ao trabalho acadêmico.

Entre mulheres brancas, não brancas e homens não brancos, 56,5\% relataram gastar entre três e seis horas diárias com trabalho doméstico. Essa média cai bastante quando se consideram apenas os homens brancos: 4 I, 3\% dizem gastar entre três e seis horas em trabalho doméstico, e a maioria deles $(55,3 \%)$ se concentra na opção "até duas horas" de trabalho doméstico diário.

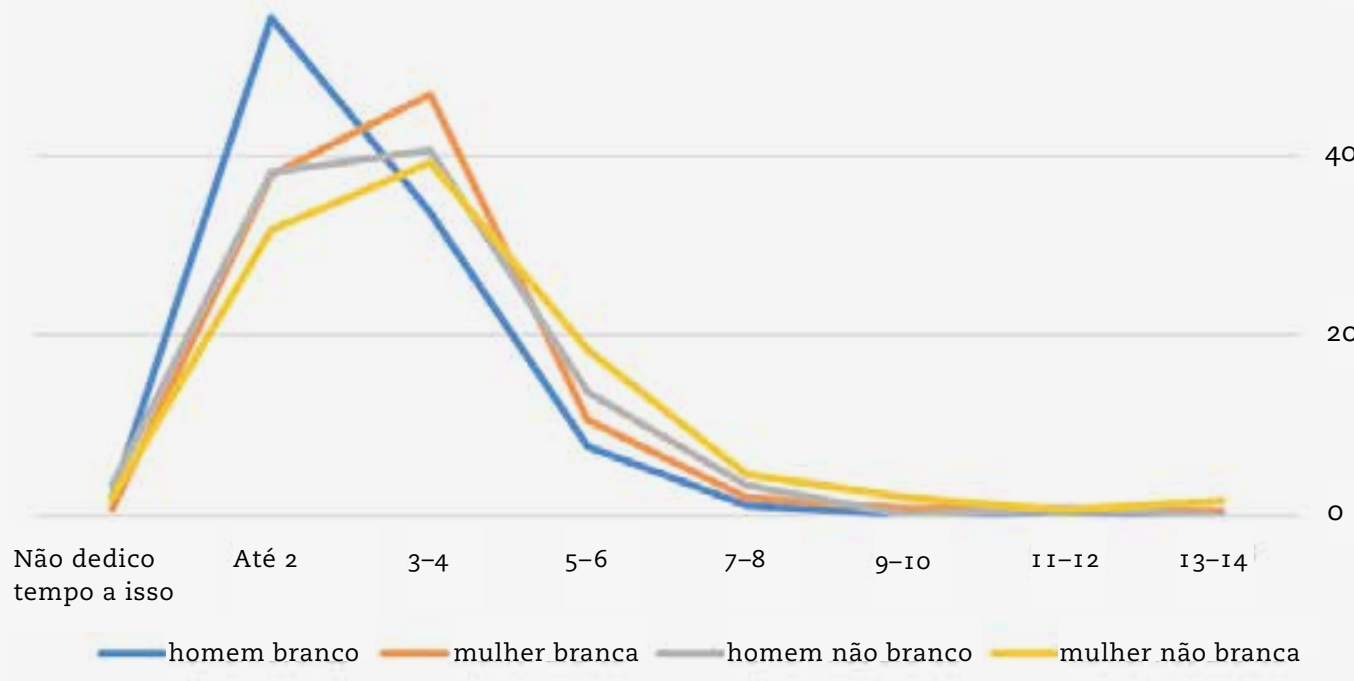


O padrão não se altera quando observamos o tempo gasto em tarefas de cuidado (Gráfico I2). Homens brancos são aqueles que mais informam não dedicar tempo a isso, e mulheres não brancas as que menos concordaram com essa afirmação. Cerca de $40 \%$ dos entrevistados afirmaram dedicar até duas horas por dia às tarefas de cuidado, sendo que mulheres não brancas dedicam em média tempo maior. Outros $20 \%$ afirmam dedicar entre três e quaro horas a esse tipo de tarefa. Se observarmos a distribuição por gênero e raça das horas dispendidas nas tarefas de cuidado, homens brancos e mulheres não brancas estão em posições mais afastadas da média geral - e opostas, o que é mais significativo. Na média geral, $26,2 \%$ dos(as) respondentes não dedicam tempo a tarefas de cuidado; mas essa resposta foi de $35,2 \%$ entre homens brancos e I $5,9 \%$ entre mulheres não brancas. Entre aquelas pessoas que dedicam de cinco a seis horas diárias a essas atividades, a média entre mulheres brancas, não brancas e homens não brancos é de $7,2 \%$, mas somente $3,8 \%$ entre os homens brancos.

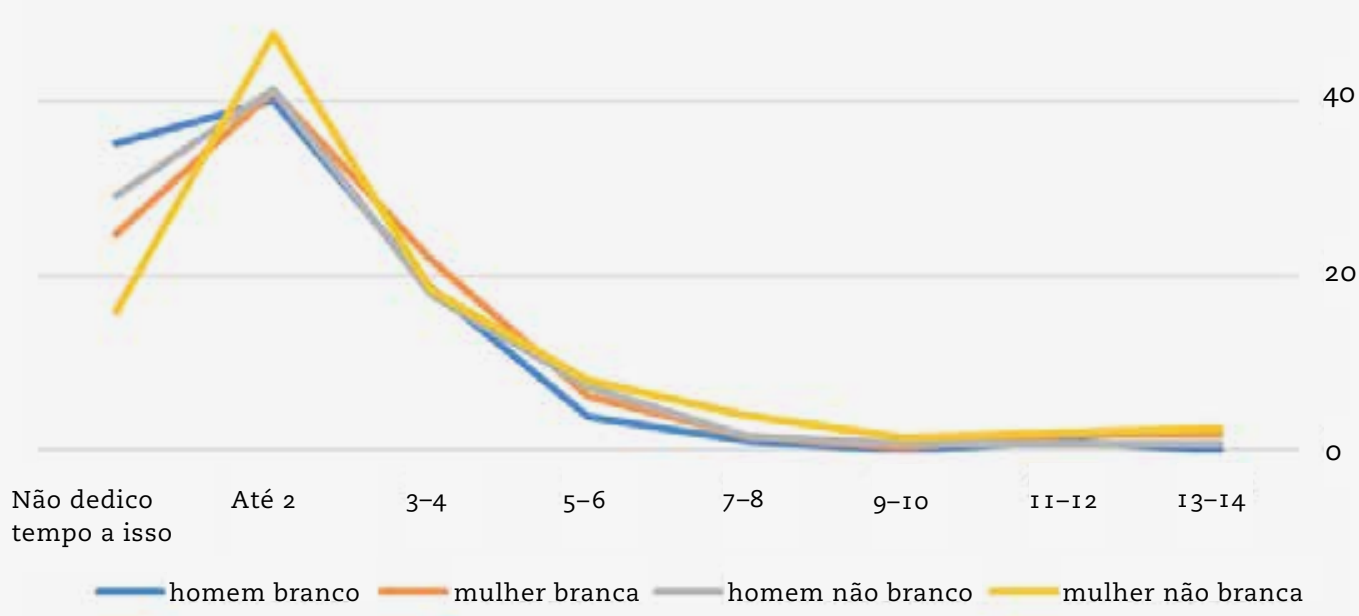

Gráfico I 2

Uso do tempo (em horas) em tarefas de cuidado por raça e gênero (\%) 
A análise da divisão de trabalho entre pessoas com ou sem filhos(as), apresentada na Tabela 4, mostra que pesquisadores(as) com filhos(as) relatam, em sua maioria (59\%), dividir o trabalho doméstico com o/a companheiro(a); I $9 \%$ dividem o trabalho com outras pessoas que moram na casa e I7\% afirmam ser os/as únicos(as) responsáveis pelo trabalho doméstico. A porcentagem de pesquisadores(as) que possuem filhos(as) e são os/as únicos(as) responsáveis pelo trabalho doméstico é de $17 \%$, bem superior àquela apresentada pelos(as) pesquisadores(as) sem filhos, que cai para $7 \%$. Os/as que não possuem filhos(as) dividem esse trabalho com o/a companheiro(a) ou com outras pessoas que moram na casa.

\begin{tabular}{l|c|c}
$\begin{array}{l}\text { Único(a) responsável trabalho doméstico } \\
\text { entre quem não mora sozinho(a) }\end{array}$ & $\begin{array}{l}\text { Sem } \\
\text { filhos(as) }\end{array}$ & $\begin{array}{l}\text { Com } \\
\text { filhos(as) }\end{array}$ \\
\hline Não, divido com meu/minha marido/esposa & 42 & 59 \\
\hline Não, divido com outras pessoas que moram comigo & 47 & I9 \\
\hline Sim & 7 & I7 \\
\hline Não, contrato trabalhador(a) doméstico(a) & 2 & 3 \\
\hline NR & I & I \\
\hline Não faço trabalho doméstico & I & I \\
\hline
\end{tabular}

Tabela 4

Divisão do trabalho entre pessoas com e sem filhos(as) (\%)

Com relação à divisão de trabalho entre homens e mulheres na casa, a pesquisa perguntou se os(as) cientistas sociais consideram a divisão de trabalho equilibrada. Os resultados, indicados no Gráfico I3, demonstram que mais da metade das pesquisadoras afirmam que "não, pois elas trabalham muito mais". Essa porcentagem cai para I $5 \%$ e $25 \%$ para homens brancos e não brancos, respectivamente. A percepção dominante entre os pesquisadores é de que a divisão de trabalho é equilibrada ( $50 \%$ e $40 \%$, brancos e não brancos). Apenas $25 \%$ afirmam que a divisão de trabalho não é equilibrada e que eles trabalham menos do que as demais pessoas da casa. Esse dado revela a sobrecarga de trabalho com atividades de cuidado e domésticas para as mulheres, mas também a percepção distinta entre elas e eles de como essa divisão se dá e do que significa uma divisão "equilibrada". É algo que pode indicar que a prevalência de estereótipos e práticas de responsabilização desigual pelo trabalho doméstico e de cuidado reduz até mesmo a visibilidade dessas demandas para os homens. 


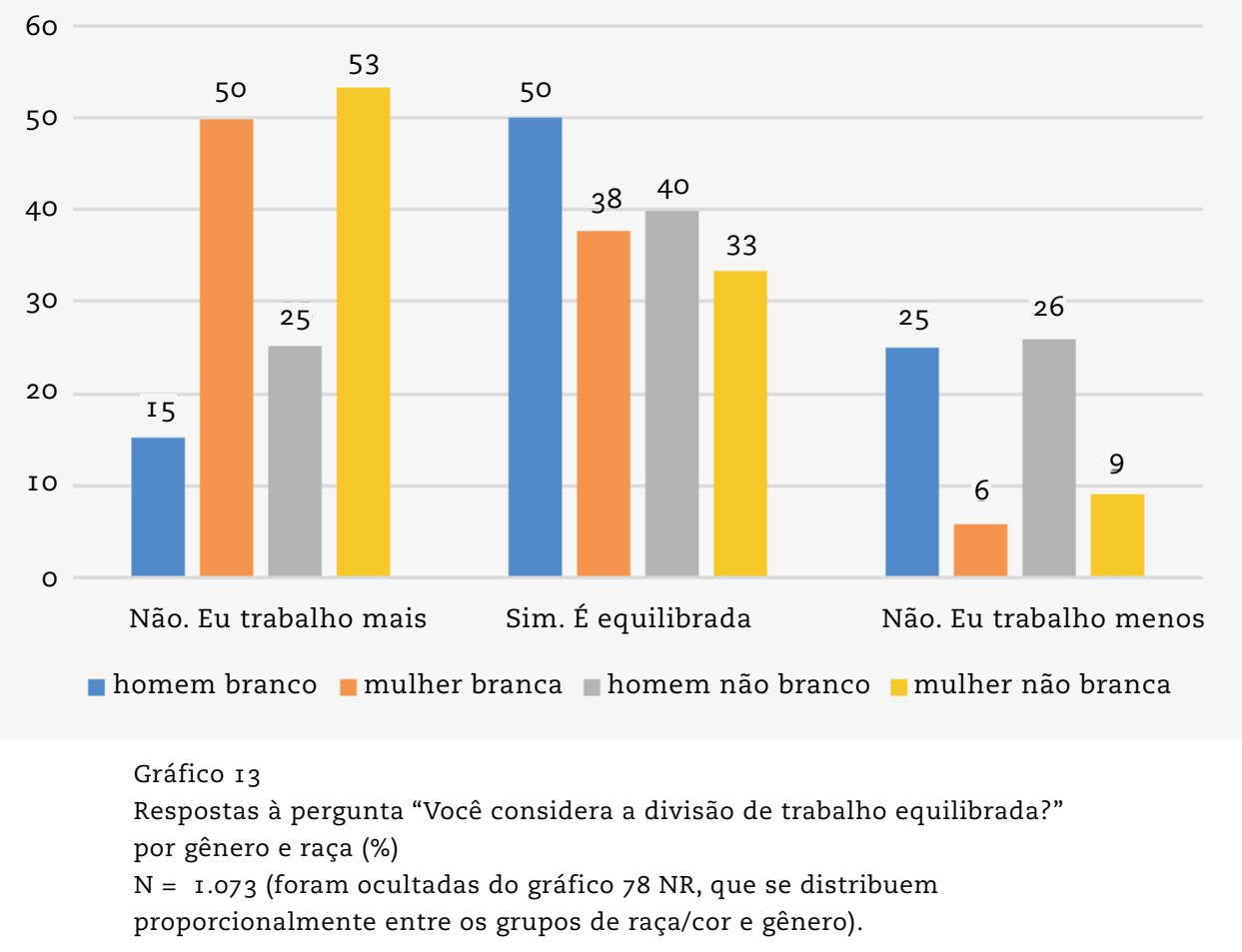

\section{O tempo para o trabalho acadêmico e administrativo}

Há uma diferença racial no tempo dedicado ao trabalho acadêmico, como pode ser visto no Gráfico I4 (na página seguinte): não brancos(as) informam, com maior frequência, gastar até duas horas com esse tipo de trabalho. Já a categoria que mais concentra brancos(as), sejam homens ou mulheres, é a de três a quatro horas diárias de trabalho acadêmico na pandemia.

Em relação ao trabalho administrativo, por seu turno, não se percebem diferenças entre os grupos raciais e de gênero, sendo que $42,8 \%$ dos(as) respondentes não dedica tempo a isso. Quando controlamos pela parentalidade, esse quadro se transforma: a média entre respondentes que têm filhos(as) na amostra é de $36,9 \%$, sendo que $4 \mathrm{I}, 2 \%$ deles(as) dedicam até duas horas diárias a trabalho administrativo - enquanto o fazem 35, I\% de quem não tem filhos(as). Aqui nossa hipótese é de que não é a parentalidade o fator que impacta nossa amostra, mas o perfil profissional de quem tem filhos(as): como já indicado, $59,6 \%$ dos(as) respondentes com filhos(as) são docentes. 


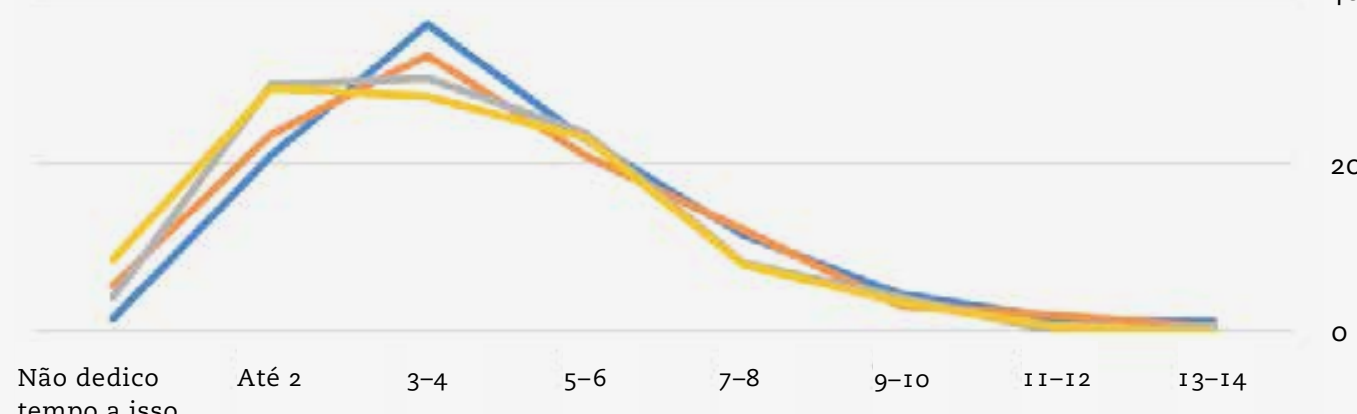

tempo a isso

homem branco

mulher branca

homem não branco

mulher não branca

Gráfico I4

Tempo (em horas) de trabalho acadêmico por raça e gênero (\%)

\section{O TEMPO PARA O LAZER}

Além de examinar o tempo dispendido com trabalho doméstico, cuidado e trabalho acadêmico, a pesquisa buscou analisar a distribuição do tempo de lazer dos(as) respondentes durante a crise do novo coronavírus. Tratando-se dos grupos de raça e de gênero, foi possível observar que, em média, I9\% dos(as) respondentes afirmaram não dedicar nenhum tempo a tais atividades. Quando controladas as variáveis gênero e raça, no entanto, verifica-se que esse percentual é menor entre homens brancos (1 2,5\%) e maior entre mulheres não brancas $(26,4 \%)$. Na categoria "até duas horas", mulheres e homens brancos(as) têm cerca de dez pontos percentuais a mais do que não brancos(as). Nas categorias com mais tempo dedicado ao lazer, homens (brancos e não brancos) são mais frequentes do que as mulheres - entre as pessoas que gastam de cinco a seis horas por dia em atividades de lazer na pandemia, 4,6\% são homens, enquanto I, $6 \%$ são mulheres. 


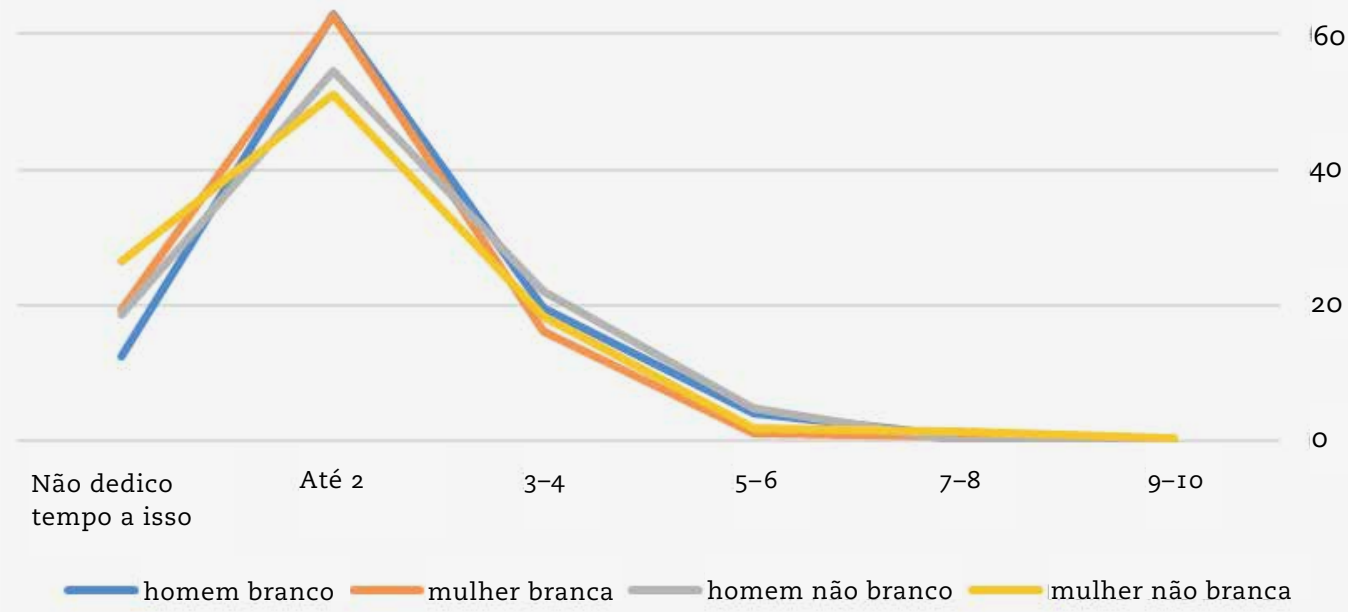

Gráfico I5 Tempo (em horas) para lazer por raça e gênero (\%)

Destacamos ainda que cuidar de alguém interfere diretamente no acesso ao lazer. Apenas I $2,5 \%$ dos(as) respondentes que declararam não cuidar de outra pessoa não dedicam tempo a atividades de lazer, enquanto esse percentual é superior entre quem cuida de filhos(as) e de idosos(as) - 3I\% e $26,3 \%$, respectivamente. Em média, 59,6\% dos(as) respondentes (sem variações grandes entre quem cuida ou não) dedicam até duas horas ao lazer, mas $22,7 \%$ dos que não cuidam de outras pessoas gastam entre três e quatro horas em atividades de lazer, enquanto esse percentual é de apenas $7 \%$ entre respondentes que cuidam de filhos(as).

\section{CONSIDERAÇÕES FINAIS}

O presente artigo analisou as consequências da pandemia da covid-I 9 no trabalho acadêmico de cientistas sociais de diferentes disciplinas. O trabalho se baseou em um survey online que contou com I.073 respondentes da antropologia, ciência política, sociologia, das relações internacionais e, em menor grau, de outras disciplinas das humanidades. Raça e gênero têm efeito na maior parte das dimensões analisadas. Há, também, distinções relevantes entre as áreas do conhecimento examinadas. As consequências da crise recente tendem a repercutir de maneira distinta, com áreas como a antropologia sendo mais prejudicadas em termos de condução de seus métodos tradicionais de pesqui- 
sa; mulheres, especialmente negras, mais sobrecarregadas com as rotinas de trabalho, e homens brancos mantendo vantagens no desenvolvimento profissional, mesmo declarando prejuízos nesse cenário de crise.

Nosso estudo tratou apenas dos grandes grupos populacionais entre os cientistas sociais. É necessário mais investimento nas agendas de pesquisa que abordem a participação de parcelas minoritárias entre os/as acadêmicos(as), como os autodeclarados amarelos e indígenas ou as pessoas trans. Entendemos, contudo, que as desigualdades reveladas dentro dos limites deste trabalho podem também nos ajudar a ampliar o debate e, com a realização de novas investigações, abordar aspectos específicos. Explicitar as vantagens das pessoas privilegiadas e dominantes em espaços de poder contribui para desvelar a suposta neutralidade das instituições que avaliam desempenhos ou definem parâmetros de seletividade sem consideração de disparidades de condições e trajetórias.

A partir dos resultados esboçados, destacamos três possíveis repercussões nas relações profissionais, que requerem especial atenção: em primeiro lugar, a comunidade acadêmica como um todo declarou aumento nas demandas de trabalho. Ao contrário do que poderia ser esperado, os docentes permaneceram tendo altas taxas de produtividade. É provável que isso acarrete estafa e desafios à saúde mental, sobretudo dos grupos que possuem menor acesso a atividades de lazer e estão sobrecarregados com as funções de cuidado e as tarefas domésticas. Em contrapartida, os pós-graduandos experimentam a crise sanitária expostos à insegurança de como se darão as oportunidades profissionais. É evidente, todavia, que tal cenário não deriva apenas da pandemia, mas também da conjuntura política de desmonte da ciência e tecnologia, redução do financiamento para pesquisas e de bolsas de pós-graduação, incertezas e, ainda, ataques voltados de maneira específica às humanidades e às ciências sociais.

Por fim, as mudanças abruptas na socialização desde março de 2020 no Brasil e antes ainda em outras partes do mundo, demandam acompanhar quais caminhos serão factíveis para modos de pesquisa estruturados por métodos que se tornaram inviáveis em seus formatos tradicionais. As interações entre docentes e discentes também foram modificadas profundamente pelo ensino online, algo que atingiu também os eventos científicos, que são fundamentais ao diálogo acadêmico. A relação dos(as) cientistas com as redes e os meios virtuais está mudando, e, durante esse processo, também tem sido denunciada a violência de grupos de extrema-direita que promovem ataques online. Para dar somente um exemplo, alguns/algumas pesquisadores(as) brasileiros(as) da área dos estudos de gênero e de raça tiveram repetidas vezes seus eventos interrompidos pela invasão de hackers.

Excetuando as peculiaridades do momento, em que a pandemia impõe modificações e nos pressiona a estar mais presentes nas interações online, os dados sobre as desigualdades apresentados demonstram a relevância de se manter e expandir políticas como as ações afirmativas para negros(as) nos aces- 
sos à graduação, aos cursos de pós-graduação e aos concursos públicos. A invisibilidade do racismo estrutural e das relações de gênero no âmbito acadêmico colabora para sua reprodução. Como disse a socióloga Joan Acker (I990), quando as organizações profissionais avaliam seus/suas integrantes pressupondo um trabalhador abstrato, elas contribuem para reproduzir as condições de vida do gênero masculino. Isso precisa ser dito em relação às vantagens da branquitude.

Recebido em 20/I0/2020 | Revisto em I 2/03/202I | Aprovado em 06/05/202I

Marcia Rangel Candido é doutora pelo Instituto de Estudos Sociais e Políticos da Universidade do Estado do Rio de Janeiro, com bolsa Capes/PDSE para período sanduíche na Universidade de Cambridge. É editora assistente de Dados. É autora e coautora de artigos sobre gênero e desigualdades na ciência política, política latinoamericana, comunicação política e representação no cinema brasileiro. Principal publicação: "Cartografia das pioneiras da ciência política no

Brasil".

Danusa Marques é professora do Instituto de Ciência Política da Universidade de Brasília, do qual atualmente é diretora, e credenciada como orientadora no Programa de Pós-Graduação em Ciência Política. Editora da área de ciência política da Revista Brasileira de Ciências Sociais.

Pesquisadora do Núcleo de Pesquisa Flora Tristán: Representações,

Conflitos e Direitos (UnB), realiza pesquisas na área de gênero, carreiras e elites políticas. Co-organizadora do livro Feminismos em rede.

Vanessa Elias de Oliveira é professora-associada da Universidade Federal do $A B C$, dos programas de pós-graduação em Políticas Públicas e em Planejamento e Gestão do Território, e pesquisadora do CNPq. Doutora em ciência política pela Universidade de São Paulo. Co-organizadora do livro Mulheres, poder e ciência política.

Flávia Biroli é doutora em história pela Unicamp e professoraassociada do Instituto de Ciência Política da Universidade de Brasília. Foi presidenta da Associação Brasileira de Ciência Política (2018-2020), editora da Revista Brasileira de Ciência Política (2009-2017) e editora assistente da revista Politics \& Gender (2017-20I8). É autora, entre outros livros, de Autonomia e desigualdades de gênero e de Gênero e desigualdades:

limites da democracia no Brasil, assim como coautora de Gênero, neoconservadorismo e democracia. 


\section{NOTAS}

* As autoras agradecem o apoio das associações profissionais (ABCP, Anpocs, ABA, Abri e SBS) na difusão do survey que originou o presente trabalho. Agradecem também aos/ às diversos(as) colegas as opiniões durante o processo de formulação e desenvolvimento da pesquisa, bem como aos/às anônimos(as) pareceristas da revista, cujas contribuições enriqueceram o artigo.

I Miceli agora atende pelo sobrenome de Kebauy.

2 A apresentação de dados sobre disparidade de gênero na autoria das submissões de artigos científicos é frequente em revistas estrangeiras das ciências sociais, mas ainda rara no Brasil. Durante a pandemia, editoras da American Journal of Political Science divulgaram resultados sobre o fluxo editorial da revista, assim como editoras(es) de periódicos da International Studies Association (ISA) (Dolan \& Lawless, 2020; Wiegand et al., 2020) No país, contamos com informações detalhadas das oscilações por gênero nas submissões de ciências sociais durante a pandemia apenas para a revista Dados (Candido \& Campos, 2020).

3 Número de programas por área de avaliação Capes em 20I9: ciência política e relações internacionais: 59; sociologia: 52; antropologia e arqueologia: 37. Disponível em: https://www.gov.br/capes/pt-br/centrais-de-conteudo/ ciencia-politica-rel-internacionais-pdf. Acesso em o2 set. 2020. Vale ponderar, entretanto, como explícito no Anexo I, que a sociologia ainda possui o maior quadro de discentes e docentes.

4 Cada disciplina das ciências sociais possui distribuição distinta, mas é significativa a liderança do Sudeste na quantidade de programas de pós-graduação em CP\&RI e em sociologia, bem como do Nordeste na antropologia. Para consultar o total de programas em cada região veja os documentos de área de 2019 .

5 A Tabela 3 apresenta apenas as respostas mais recorrentes. Para dados detalhados e pormenorizados, cf. o Anexo 3 deste artigo.

6 Ressalta-se que o questionário foi aplicado entre junho e julho de 2020, então esse cenário pode ter se transformado bastante, evidentemente, até a publicação deste estudo. 


\section{REFERÊNCIAS}

Acker, Joan. (1990). Hierarchies, jobs, bodies: a theory of gendered organizations. Gender and Society, 5/2, P.I39-I58. Allen, Nicholas \& Savigny, Heather. (2016). Experiencing gender in UK political science: the results of a practitioner survey. The British Journal of Politics and International Relations, I8/4, p. 997-IoI5.

Atkinson, Hannah et al. (20I8). Race, etnhnicity \& equality in UK history: a report and resource for change. Royal Historical Society.

Biroli, Flávia. (2016). Divisão sexual do trabalho e democracia. Dados, 59/3, p. 719-754.

Breuning, Marijke et al. (2020). The great equalizer? Gender, parenting, and scholarly productivity during the global pandemic. APSA Preprints. Disponível em: doi: I0.33774/ apsa-2020-ffg5r. Acesso em 02 set. 2020.

Candido, Marcia Rangel \& Campos, Luiz Augusto. (2020). Pandemia reduz submissões de artigos acadêmicos assinados por mulheres. Blog da Dados. Disponível em: http://dados. iesp.uerj.br/pandemia-reduz-submissoes-de-mulheres/. Acesso em 02 set. 2020.

Candido, Marcia Rangel; Feres Júnior, João \& Campos, Luiz Augusto. (20I9). Desigualdades de gênero na elite da ciência política brasileira. Civitas, Revista de Ciências Sociais. Disponível em: https://doi.org/Io.I5448/1984-7289.2019.3.33488. Acesso em 02 set. 2020.

Castro, Bárbara \& Chaguri, Mariana. (2020). Um tempo só para si: gênero, pandemia e uma política científica feminista. Blog da Dados. Disponível em: http://dados.iesp.uerj.br/ pandemia-cientifica-feminista/. Acesso em 02 set. 2020.

Cui, Ruomeng; Ding, Hao \& Zhu, Feng. (2020). Gender inequality in research productivity during the covid-I9 pandemic. Social Science Research Network. Disponível em: https:// ssrn.com/abstract=3623492 or http://dx.doi.org/ro.2139/ ssrn.3623492. Acesso em 02 set. 2020.

Dolan, Kathleen \& Lawless, Jennifer. (2020). It takes a submission: gendered patterns in the pages of AJPS. American Journal of Political Science. Disponível em: https://ajps. org/2020/04/20/it-takes-a-submission-gendered-patternsin-the-pages-of-ajps/. Acesso em 02 set. 2020. 
IBGE. (2018). Outras formas de trabalho 20I8. Pesquisa Nacional por Amostra de Domicílios Contínua, Diretoria de Pesquisas, Coordenação de Trabalho e Rendimento, Instituto Brasileiro de Geografia e Estatística. Disponível em https:// biblioteca.ibge.gov.br/visualizacao/livros/livior650_informativo.pdf. Acesso em 03 set. 2020.

Michetti, Heloísa Helena \& Miceli, Maria Teresa. (1969). A situação do ensino e pesquisa de ciência política no Brasil. Revista de Ciência Política, 2/4, p. 89-ı ıo.

Myers, Kyle et al. (2020). Unequal efects of the covid-I9 pandemic on scientists. Nature Human Behaviour. Disponível em: https://go.nature.com/2EnDWxq. Acesso em 02 set. 2020. Norris, Pippa. (2020). Gender gaps in political science research productivity. Research papers. Disponível em: https:// www.pippanorris.com/new-research-papers. Acesso em 02 set. 2020.

Novkov, Julie \& Barclay, Scott. (2010). Lesbians, gays, bisexuals, and the transgendered in political science: report on a discipline-wide survey. Political Science \& Politics. Disponível em: doi:Io.Ior7/Si049096509990643. Acesso em 02 set. 2020. Palumbo, Mariana. (2017). Pensar(nos) desde adentro: representaciones sociales y experiencias de género. San Martín: Unsam Edita.

Staniscuaski, Fernanda et al. (2020). Gender, race and parenthood impact academic productivity during the covid-I9 pandemic: from survey to action. Disponível em: https://doi.org/Io.I IoI /2020.07.04.187583. Acesso em 02 set. 2020.

USP Mulheres. (20I8). Interações na USP: primeiros resultados da pesquisa. São Paulo, jun. 2018. Disponível em: http:// uspmulheres.usp.br/wp-content/uploads/sites/I45/2018 /07/INTERA\%C3\%87\%C3\%95ES-NA-USP_final_publica\% ${ }_{3}$ \%A7\%C3\%A302407.pdf. Acesso em 02 set. 2020.

Vallejo, Agustín. (20I7). El XIII Congreso Nacional de Ciencia Política. Revista SAAP, II/2.

Wiegand, Krista et al. (2020). Journal submissions in times of covid-I9: is there a gender gap?. Duck of Minerva. Disponível em: https://duckofminerva.com/2020/05/journal-submissions-in-times-of-covid-r9-is-there-a-gender-gap.html. Acesso em 02 set. 2020. 


\begin{tabular}{|c|c|c|c|c|c|c|}
\hline \multirow[b]{2}{*}{$\begin{array}{l}\text { Docentes } \\
\text { permanentes }\end{array}$} & \multicolumn{6}{|c|}{ Área de avaliação da Capes } \\
\hline & $\begin{array}{l}\text { Antropologia/ } \\
\text { Arqueologia }\end{array}$ & $\%$ & $\begin{array}{l}\text { Ciência política/ } \\
\text { Relações } \\
\text { internacionais }\end{array}$ & $\%$ & Sociologia & $\%$ \\
\hline Feminino & 274 & 49 & 289 & 34 & 458 & 45 \\
\hline Masculino & $28 \mathrm{I}$ & $5 \mathrm{I}$ & $55 \mathrm{I}$ & 66 & 553 & 55 \\
\hline Total & 555 & IOO & 840 & 100 & I.OI I & IOO \\
\hline Doutorado & $\begin{array}{l}\text { Antropologia/ } \\
\text { Arqueologia }\end{array}$ & $\%$ & $\begin{array}{l}\text { Ciência política/ } \\
\text { Relações } \\
\text { internacionais }\end{array}$ & $\%$ & Sociologia & $\%$ \\
\hline Feminino & 679 & 56 & 563 & 45 & I. 273 & $5 I$ \\
\hline Masculino & $53 \mathrm{I}$ & 44 & 675 & 55 & I. 237 & 49 \\
\hline Total & I. 210 & IOO & I. 238 & IOO & 2.510 & IOO \\
\hline Mestrado & $\begin{array}{l}\text { Antropologia/ } \\
\text { Arqueologia }\end{array}$ & $\%$ & $\begin{array}{l}\text { Ciência política/ } \\
\text { Relações } \\
\text { internacionais }\end{array}$ & $\%$ & Sociologia & $\%$ \\
\hline Feminino & 843 & 57 & I. 337 & 50 & I. 484 & 55 \\
\hline Masculino & 625 & 43 & I.3I3 & 50 & I. 233 & 45 \\
\hline Total & I. 468 & IOO & 2.650 & IOO & 2.717 & IOO \\
\hline
\end{tabular}

Proporção de discentes e docentes das pós-graduações nas grandes áreas das ciências sociais em 2019 Fonte: elaborado pelas autoras com base em dados da Plataforma Sucupira. 


\begin{tabular}{|c|c|c|}
\hline Ocupação & $\mathrm{N}$ & $\%$ \\
\hline Docente de universidade pública & 345 & 32,2 \\
\hline Estudante de pós-graduação bolsista & 275 & 25,6 \\
\hline Estudante de pós-graduação sem bolsa & I73 & I6,I \\
\hline Docente de universidade privada & 92 & 8,6 \\
\hline Pesquisador(a) autônomo(a) & 92 & 8,6 \\
\hline Freelancer & 89 & 8,3 \\
\hline Pesquisador(a) com vínculo formal & 59 & 5,5 \\
\hline Recém-formado(a) e desempregado(a) & 48 & 4,5 \\
\hline Pós-doutorando(a) com bolsa & 32 & 3 \\
\hline Docente na educação básica & $3 I$ & 2,9 \\
\hline Servidor(a) público(a), exceto docente & 25 & 2,3 \\
\hline Assalariado(a) no mercado de trabalho privado, exceto docente & 22 & $2, \mathrm{I}$ \\
\hline Pós-doutorando(a) sem bolsa & 20 & $\mathrm{I}, 9$ \\
\hline Docente de instituto federal e educação tecnológica & 8 & 0,7 \\
\hline Docente substituto(a) de instituição pública & 6 & 0,6 \\
\hline Aposentado(a) & 4 & 0,4 \\
\hline Bolsista de projeto de pesquisa ou ensino & 4 & 0,4 \\
\hline Desempregado(a) & 3 & 0,3 \\
\hline Docente colaborador(a) de universidade pública & 2 & 0,2 \\
\hline Docente visitante de universidade pública & I & $\mathrm{O}, \mathrm{I}$ \\
\hline Total & I.33I & - \\
\hline
\end{tabular}


A pandemia prejudicou minha organização para trabalhar, pois gasto mais tempo cuidando da casa e/ou da família

A pandemia provavelmente me fará não cumprir prazos, porque afetou globalmente minha organização do trabalho

A pandemia mudou minhas perspectivas de futuro, pois não sei como serão os prazos da pós-graduação

\begin{tabular}{ll}
\hline A pandemia aumentou minhas demandas de trabalho acadêmico & 35 \\
\hline A pandemia adiou concursos públicos que eu ia tentar & 25 \\
\hline A pandemia aumentou minhas demandas de trabalho administrativo & 24 \\
\hline $\begin{array}{l}\text { A pandemia prejudicou minhas oportunidades para entrada no } \\
\text { mercado de trabalho na iniciativa privada }\end{array}$ & I5 \\
\hline A pandemia me fez perder trabalhos remunerados & I3 \\
\hline $\begin{array}{l}\text { A pandemia não alterou minhas demandas de trabalho, pois sigo } \\
\text { dando aulas online e/ou fazendo trabalho remoto }\end{array}$ & I2 \\
\hline $\begin{array}{l}\text { A pandemia melhorou meu tempo para produzir artigos, pois não } \\
\text { preciso mais dar aulas }\end{array}$ & I2 \\
\hline $\begin{array}{l}\text { A pandemia me fez interromper estágios de pesquisa em instituições } \\
\text { estrangeiras }\end{array}$ & 7 \\
\hline \begin{tabular}{l} 
Outros: menções variadas \\
\hline Não me identifico com nenhuma das afirmações acima
\end{tabular} & 7 \\
\hline $\begin{array}{l}\text { A pandemia provavelmente me fará não cumprir prazos, porque eu } \\
\text { adoeci de covid-r9 }\end{array}$ & 3 \\
\hline $\begin{array}{l}\text { A pandemia afetou negativamente minha saúde mental* } \\
\text { adaptar todo o conteúdo para aulas online e trabalho remoto* }\end{array}$ & I \\
\hline $\begin{array}{l}\text { A pandemia inviabilizou o trabalho de campo* } \\
\text { Total }\end{array}$ & I00 \\
\hline
\end{tabular}

*Respostas mais recorrentes no campo aberto de respostas "outros".

\section{Anexo 3}

Principais impactos da pandemia nas rotinas de trabalho (todas as respostas) 
Palavras-chave

Ciências sociais; trabalho acadêmico; pandemia; desigualdades; survey.

Keywords

Social sciences; academic work; pandemic; inequalities; survey.

\section{AS CIÊNCIAS SOCIAIS NA PANDEMIA DE COVID-19:} ROTINAS DE TRABALHO E DESIGUALDADES

\section{Resumo}

O objetivo desse texto é analisar as consequências da pandemia de covid-I 9 nas rotinas de trabalho acadêmico das ciências sociais no Brasil. O estudo se baseia em resultados de um survey difundido com o apoio de associações profissionais da antropologia, ciência política, sociologia e das relações internacionais. O artigo apresenta o perfil dos I.073 participantes e suas percepções sobre os efeitos da crise nas atividades de formação, ensino e pesquisa, bem como na divisão das tarefas do âmbito privado. Embora a maior parte dos respondentes tenha declarado sentir impactos negativos da pandemia, há disparidades por disciplina de atuação, gênero e raça. Os dados reforçam a importância da discussão de parâmetros de avaliação de produtividade sensíveis às desigualdades.

SOCIAL SCIENCES IN THE COVID-19 PANDEMIC: WORK ROUTINES AND INEQUALITIES

\section{Abstract}

The purpose of this text is to analyze the consequences of the covid-I9 pandemic in the academic work routines of Social Sciences in Brazil. The study is based on the results of a survey disseminated with the support of professional associations in Anthropology, Political Science, Sociology and International Relations. The article presents the profile of the I,073 participants and their perceptions about the effects of the crisis on training, teaching and research activities, as well as on the division of tasks in the private sphere. Although most respondents said they felt negative impacts of the pandemic, there are disparities by discipline, gender and race. The data reinforce the importance of discussing productivity evaluation parameters sensitive to inequalities. 